\title{
SIMULATION OF UNIAXIAL TENSILE BEHAVIOR OF QUASI-BRITTLE MATERIALS USING SOFTENING CONTACT MODELS IN DEM
}

\author{
Bora Pulatsu ${ }^{a 1}$, Ece Erdogmus ${ }^{a 2}$, Paulo B. Lourenço ${ }^{b}$ and Romain Quey ${ }^{c}$
}

Abstract: This study proposes new contact models to be incorporated into discrete element method (DEM) to more accurately simulate the tensile softening in quasi-brittle materials, such as plain concrete and masonry with emphasis on fracture mechanism and post-peak response. For this purpose, a plain concrete specimen (double notched) and stack bonded masonry prism under direct tensile test are modeled. Furthermore, mixed mode crack propagation is investigated in concrete and brickwork assemblages. Two modeling approaches are proposed, the simplified and detailed meso modeling, both based on DEM. In the simplified meso-model, a smooth contact surface is considered between two separate blocks, whereas the internal structure of the material is explicitly represented as a tessellation into random polyhedral blocks in the detailed meso-model. Furthermore, recently developed tensile softening contact constitutive models implemented into a commercial discrete element code (3DEC) are used to simulate the softening behavior of concrete and masonry. As an important novel contribution, it is indicated that the proposed computational models successfully capture the complete (pre- and post- peak) material behavior and realistically replicate the cracking mechanism. Additionally, a sensitivity analysis demonstrates the influence of the various micro-contact parameters on the overall response of the examined materials.

Keywords: Softening, DEM, Contact Mechanics, Masonry Prisms, Concrete, Direct Tension Test

a1 PhD Candidate, University of Nebraska-Lincoln, NE, United States

a2 Professor, University of Nebraska-Lincoln, NE, United States

b Professor, ISISE, Institute of Science and Innovation for Bio-Sustainability (IB-S), Department of Civil Engineering, University of Minho, Guimaraes, Portugal

c Associate Scientist, Mines Saint-Etienne, CNRS, France 


\section{Introduction}

Concrete and masonry are commonly used construction materials in the world. It is wellknown that both of these materials have remarkably low tensile strength, when compared to their compression capacity, which is typical for quasi-brittle materials. Although the cracking mechanism of both concrete and masonry may be considered as a local phenomenon, it affects the overall structural behavior and corresponding failure mechanism. As a result of this, predicting the response of these materials under tensile forces plays a crucial role in the structural analysis and design, both under ultimate and serviceability conditions. However, it is not straight forward to characterize the tensile fracture (mode-I) of concrete, which mainly depends on the complex internal structure of the material. This situation may be even more complicated in case of masonry prisms since the material behavior is governed by its constituents (i.e. mortar and unit) and their interaction among each other.

It is worth noting that it is quite difficult to predict crack initiation and propagation phenomena due to the irregular nature of concrete, highly influenced by the existence of pores, defects and inclusions, as well as the stiffness and geometrical difference of its components. Nonhomogeneous deformations of concrete are inherited by its disordered material characteristic. Additionally, plain concrete exhibits a softening post-peak behavior (similarly to other quasibrittle materials), indicating a gradual decrease of the mechanical resistance (or stress) with increasing deformation once it reaches its (ultimate) strength. This phenomenon is explained by the activation of micro-cracks close to the peak loads and, subsequent yielding macro-crack propagation, see (Van Mier and Man 2009). Similar to concrete, masonry units and mortar joints exhibit nonlinear softening response with complex cracking mechanisms. 
Today, several testing methods are used to measure fracture properties, namely the direct tension test, three- or four-point bending test and split tensile test (or Brazilian test). In this research, the softening regime of a plain concrete specimen and stack bonded masonry prism obtained by direct tension test is investigated numerically via validated three-dimensional (3D) discrete element models under quasi-static loading condition.

Briefly, the discrete element method (DEM), developed by (Cundall 1971), was first applied to simulate the progressive collapse mechanism of jointed rock masses. Over the last several decades, DEM has been comprehensively used in the fracture analysis of quasi-brittle materials involving some meso-scale (sometimes also referred as micro-modeling), including concrete, rock, and masonry among others (Kazerani 2013; Ghazvinian et al. 2014; Chen et al. 2018; Sarhosis and Lemos 2018). An exhaustive review of discrete modeling techniques on the fracture process in rock and rock masses can be found in (Lisjak and Grasselli 2014). Further, discrete block analogy has been applied in the macro scale (implying the structural level) to assess the structural stability of various masonry structures, i.e. arches, walls, ancient columns etc., (Lemos 2007; Pulatsu et al. 2016, 2017, 2019; Bui et al. 2017; Lemos and Campos Costa 2017).

Here, a commercial discrete element code 3DEC, developed by ITASCA, is used. Newly, developed tension-softening contact constitutive modes, written in C++ and compiled as DLL (dynamic link library) files in 3DEC, are utilized to simulate the tensile fracture mechanism. Two different representations of the concrete and masonry specimens are used with different level of complexity, in order to demonstrate the wide application of the developed tool. On one hand, in the simplified model, a smooth contact surface is defined considering two separate continuum parts, where only uniform opening is possible during numerical analysis. On the other hand, in the 
detailed model, the internal structure of the concrete and mortar joint are explicitly represented at the meso level. Both numerical approaches are validated based on previously published experimental results and several inferences are made regarding the discontinuum analysis, contact parameters, and the softening response of the concrete and masonry specimens.

As an important novel contribution, it is also demonstrated that the combination of a tessellation of large 3D blocks with proper non-linear softening laws is capable of capturing the relevant phenomena involved in the fracture of quasi-brittle materials.

\section{Benchmark Studies from Literature}

The proposed discrete element models are benchmarked with direct tension experiments of plain concrete and masonry prisms previously published in the literature, as discussed next.

\subsection{Direct Tension Test of Concrete}

To validate the concrete specimen simulations, the deformation controlled uniaxial tensile test of a double notched plain concrete specimen performed by Hordijk (Hordijk 1991) is used. This work is selected as a detailed description of the experimental setup and the preparation of the specimens are provided. The analyzed specimen has dimensions of $250 \times 60 \times 50 \mathrm{~mm}^{3}$ (length, breadth and width) with a symmetric notch $\left(5 \times 5 \mathrm{~mm}^{2}\right)$ located at the mid-length of both sides. During the experiment, pre- and post-peak response of the material and axial deformations were recorded using an electro-hydraulic machine and multiple extensometers (gauge-length of $35 \mathrm{~mm}$ ),

respectively (Figure 1a). The net cross-sectional area of the specimen $\left(50 \times 50 \mathrm{~mm}^{2}\right)$ was 
considered to calculate the stress applied on the specimen. The response of the material was plotted using the averaged results of ten extensometers (Rots 1988), as shown in Figure 1b.

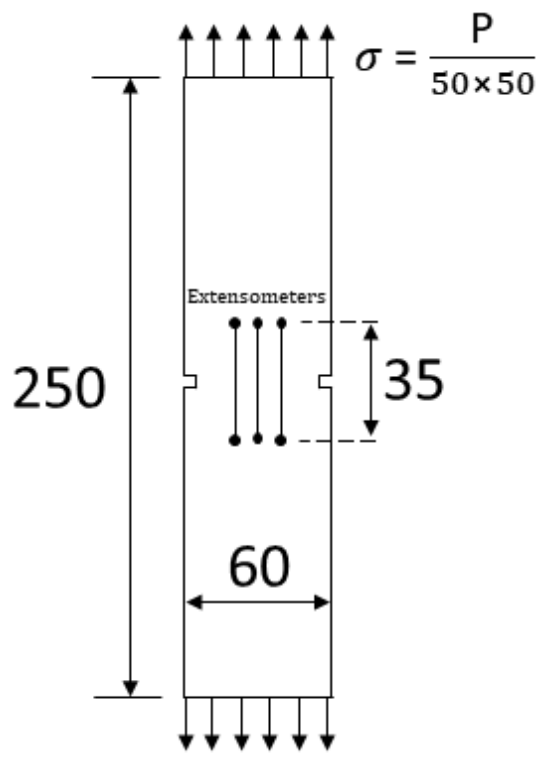

a) Illustration of direct tension test of a concrete specimen

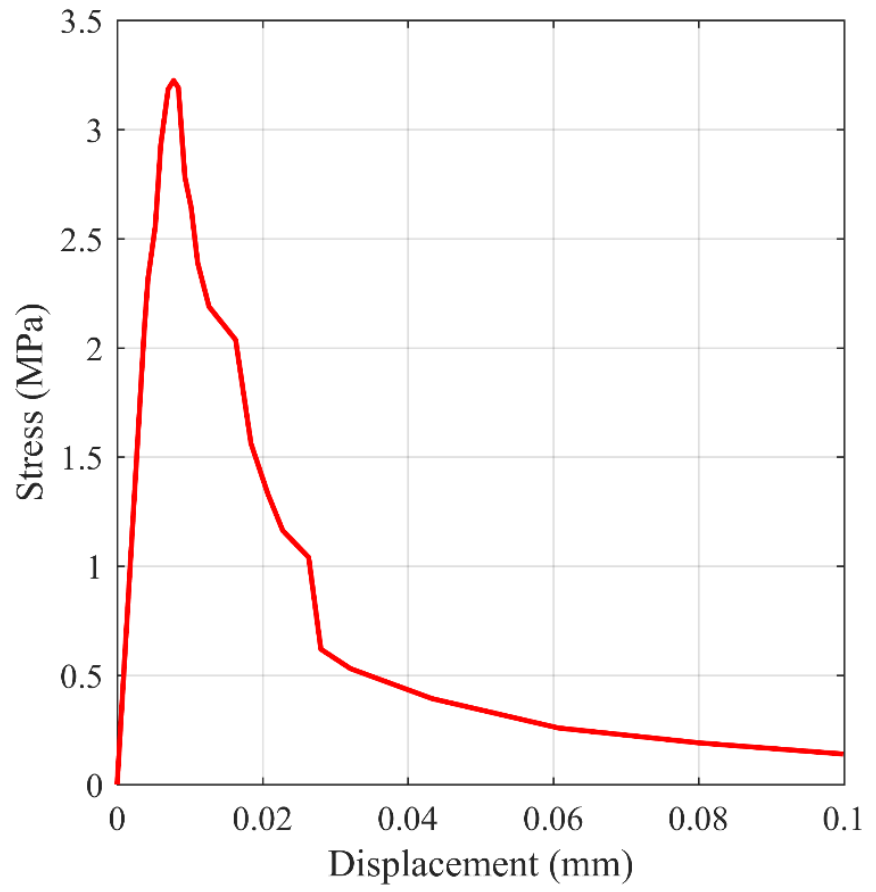

b) Stress-displacement curve obtained from the displacement controlled experiment (Hordijk 1991)

Figure 1. Benchmark study; a) tested specimen (dimensions are in $\mathrm{mm}$ ) and b) uniaxial behavior of concrete under tension.

\subsection{Direct Tension Test of Stack Bonded Masonry Prism}

More recently, tensile behavior of masonry units and unit-mortar interfaces were also explored through direct tension tests (displacement controlled) to obtain intrinsic properties of the material such as tensile strength, fracture energy and the complete stress-deformation behavior of the material by various researchers (Van der Pluijm 1997; Lourenço et al. 2005). In this research, a 
comprehensive experimental work, presented by (Van der Pluijm 1997), is utilized to validate numerical models. These authors tested stack bonded masonry prisms built by wire cut clay bricks (wc-jo) and a mortar mixture, composed of 1:1:6 proportions (Cement: Lime: Sand). The bricks were $100 \times 50 \times 50 \mathrm{~mm}$ (length $\times$ breadth $\times$ width) and mortar was $15 \mathrm{~mm}$ thick. Throughout the experiment, elongations were recorded via LVDTs, attached at the corners of the specimens (Figure 2a). Even though the results exhibited a large scatter of tensile strength and fracture energy due to the heterogeneous characteristics of masonry constituents, a trend of exponential softening can be still observed once the ultimate tensile stress is reached, as shown in Figure 2b.

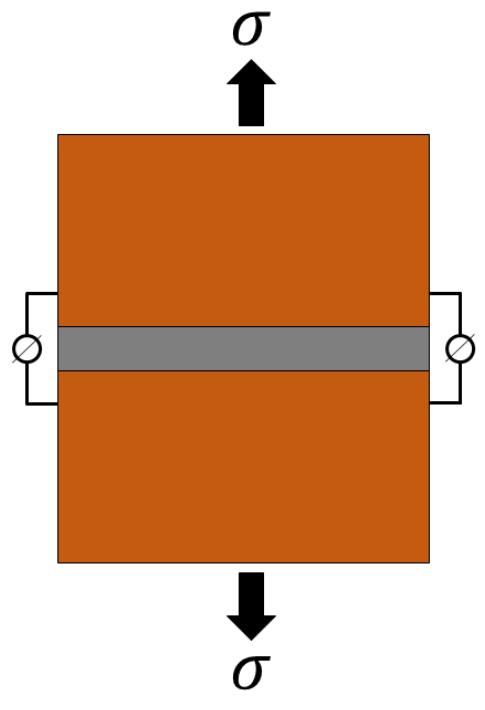

a) Direct tension test setup

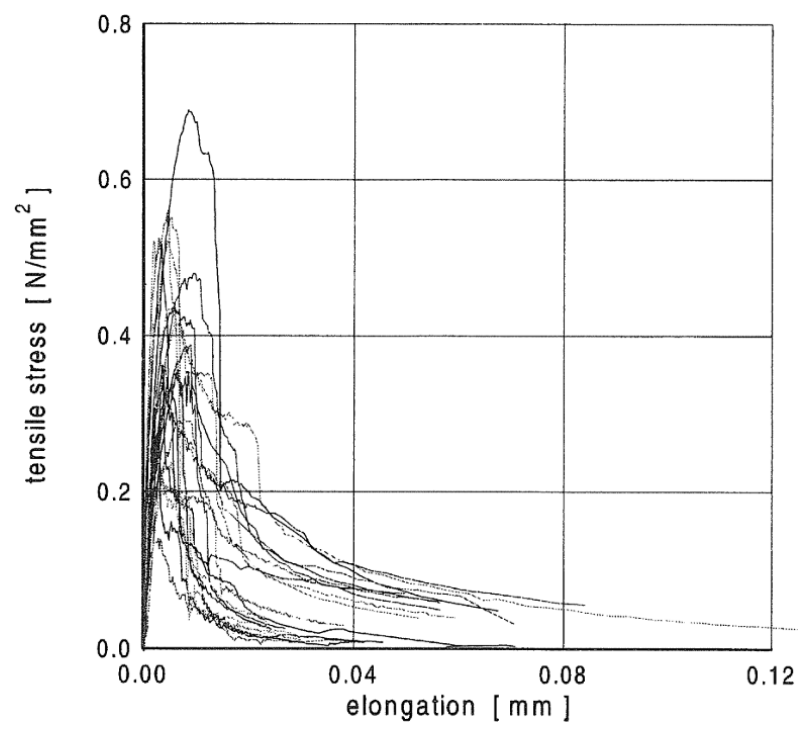

b) Stress-displacement curves (wc-jo bricks with 1:1:6 mortar) (Van der Pluijm 1997)

Figure 2. Test setup and results obtained from uniaxial tensile tests. 


\section{Discrete Modeling Strategy}

In this research, a discontinuum type of analysis is performed based on discrete element method to predict the tensile fracture mechanism of a plain concrete specimen and stack bonded masonry prism. The morphology of the concrete sample, consisting of cement paste and aggregates, is represented as a discontinuous system made up of individual polyhedral grains (or blocks). A similar strategy is followed in masonry prisms, where the mortar joint is replicated via randomly generated polyhedral blocks, however, clay bricks are considered as continuum blocks.

Deformable blocks, interacting through their contact points, with elasto-plastic contact constitutive models are used throughout the analyses. This methodology can be considered in the framework of a meso modeling strategy, since it aims to provide the tensile cracking response of the examined materials explicitly including localized cracks.

In DEM, the deformable blocks are discretized into finite-difference tetrahedral elements (referred as finite-difference zones) to introduce the internal deformation in each block. The vertices of the tetrahedral elements are called gridpoints (see Figure 3) and the equation of motion for each gridpoint is expressed in Equation 1.

$$
m \ddot{u}_{i}+\alpha m \dot{u}_{i}=\sum F_{i}
$$

where $u_{i}, m, \alpha$ and $F_{i}$ are the nodal displacement vector, the nodal mass, the massproportional viscous damping parameter and the resultant nodal force vector. The resultant nodal force vector is calculated as the sum of the external forces, contact forces and the internal nodal 
forces obtained from internal stresses in the zones. The equations of motion are solved using the central difference formula, where the time step $(\Delta t)$ is divided into equal time intervals (Equation 2). Hence the new nodal velocities are calculated via an explicit integration scheme using a local damping formulation (Cundall 1987), as given in Equation 3. The local damping forces $\left(F_{d}\right)_{i}$, opposing to motion, are proportional to the local unbalanced forces and calculated as shown in Equation 4. In the local damping formulation, a different amount of damping is required for each part of the numerical model to tackle the abrupt load changes or to capture progressive failure mechanisms. Therefore, the amount of damping varies from point to point in the model (ITASCA 2004).

$$
\begin{gathered}
\ddot{u}_{i}^{t}=\frac{\dot{u}_{i}^{t+\Delta t / 2}-\dot{u}_{i}^{t-\Delta t / 2}}{\Delta t} \\
\dot{u}_{i}^{t+\Delta t / 2}=\dot{u}_{i}^{t-\Delta t / 2}+\left[\sum F_{i}^{t}-\left(F_{d}\right)_{i}\right] \frac{\Delta t}{m} \\
\left(F_{d}\right)_{i}=\lambda\left|\sum F_{i}^{t}\right| \operatorname{sgn}\left(\dot{u}_{i}^{t-\frac{\Delta t}{2}}\right)
\end{gathered}
$$

To improve the convergence of the solution for quasi-static problems, scaled masses are used during the analyses. Additionally, to ensure numerical stability, a limited time step is set in the analysis, which may be calculated as given in Equation 5. 


$$
\Delta t=2(\text { frac })\left(\frac{m_{\min }}{k_{\max }}\right)
$$

where $f r a c, m_{\min }$ and $k_{\max }$ are the user-defined value to reduce the time step (default value is 0.1 , the smallest nodal mass and the maximum contact stiffness. The new block locations are calculated using the known nodal velocities utilizing Equation 3. Then, examining the relative deformations (in normal $\Delta u_{n}$ and shear $\Delta u_{s}$ directions) at the contact points between the blocks (Figure 3), the new normal $(\Delta \sigma)$ and shear $(\Delta \tau)$ stress increments are calculated. In the elastic range, the behavior of the contact is governed by the normal $\left(k_{n}\right)$ and shear $\left(k_{s}\right)$ stiffnesses, given in Equation 6 and 7, respectively. The obtained stress increments are added on the previous contact stresses and corrected according to the assigned failure criteria.

$$
\begin{gathered}
\Delta \sigma=k_{n} \Delta u_{n} \\
\Delta \tau=k_{s} \Delta u_{s}
\end{gathered}
$$

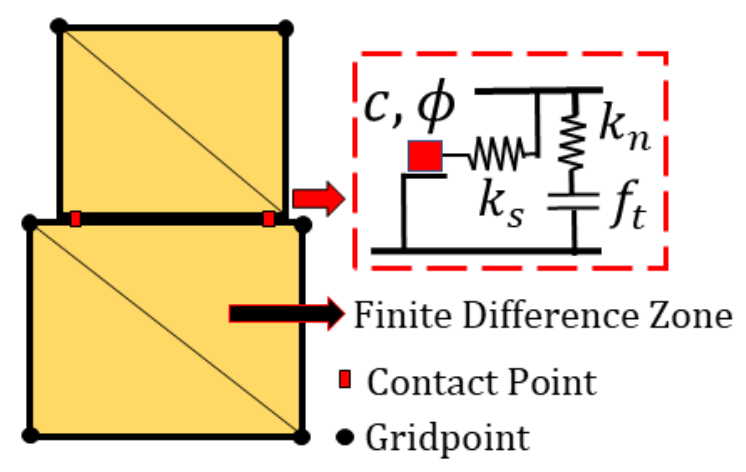

Figure 3. Representation of contact point between rectangular blocks with triangular finitedifference zones in 2D. 
In this work, the Coulomb-slip joint model and different tensile failure modes are used. There is no failure criterion set for compression, hence, compression is kept as linearly elastic. The nonlinear response of the joint is controlled by the tensile strength $\left(f_{t}\right)$ in the normal direction (Equation 8). Moreover, the cohesion (c) and friction angle $(\phi)$ parameters govern the inelastic response of the contact in the shear direction (Equation 9). A brittle shear failure is assumed by setting the cohesion and friction angle to zero once the failure is identified.

$$
\begin{gathered}
\sigma_{n} \leq f_{t} \\
|\tau| \leq c+\sigma_{n} \tan \phi
\end{gathered}
$$

Moreover, dilatancy is taken into consideration once the shear failure occurs at the contact by introducing the dilation angle $(\psi)$ as shown in Equation 10. Then, the normal stress is modified according to the effect of dilation via Equation 11.

$$
\begin{aligned}
& \Delta u_{n, \text { dilatation }}=\Delta u_{s} \tan \psi \\
& \Delta \sigma_{\text {total }}=\Delta \sigma+\Delta u_{s} \tan \psi
\end{aligned}
$$

Finally, the obtained contact stresses are multiplied with the contact area (contact length in 2D) and used in the equations of motion (3). The dynamic calculation cycle of the executed numerical procedure is schematized in Figure 4. 


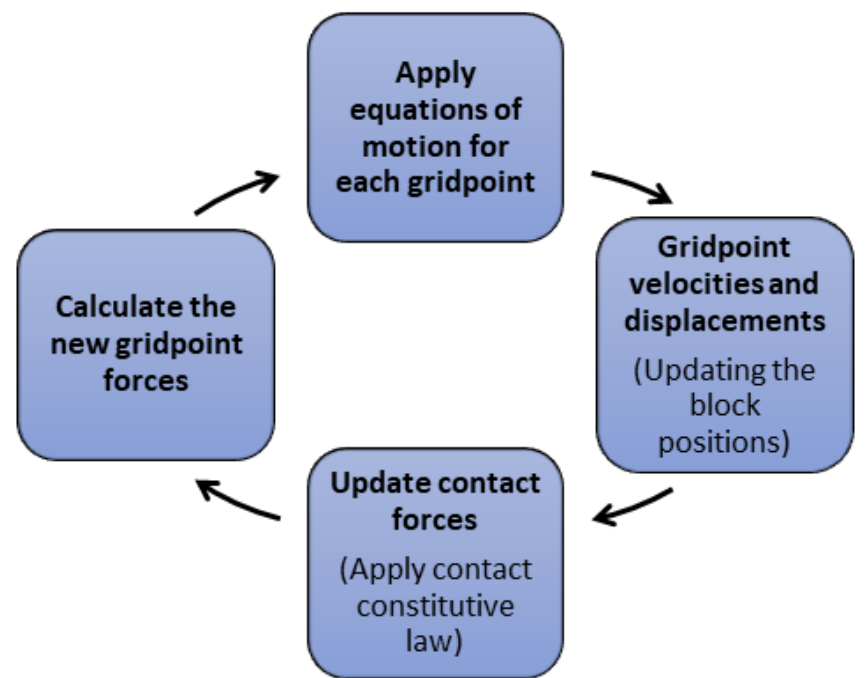

Figure 4. Dynamic calculation cycle performed in 3DEC.

\subsection{Contact Constitutive Laws in Tension}

The mechanical behavior of the proposed discontinuous system is governed by the contact constitutive laws and solid polyhedral blocks. Here, nonlinear response of the numerical model is governed by the joints (or contacts), where polyhedral blocks are fully elastic. In other words, all possible failure mechanisms, i.e. sliding, contact opening and detachment, are lumped at the interaction surface among the elastically deformable polyhedral blocks.

In the following, two different softening contact models, linear and polynomial, are proposed in addition to the available tension cut-off model in the commercial software, 3DEC (Figure 5). There are three main goals to implement the new tension softening contact models; $(i)$ eliminating the extremely brittle response of the existing tension cut-off model; (ii) capturing not only the prepeak response but also the post-peak behavior of the material; and (iii) minimizing the influence of mesh and particle size dependency of the results by including tensile fracture energy, $\left(G_{f}\right)$ into the formulation of the contact constitutive law. In shear, the Coulomb slip joint model is used 
requiring cohesion and friction angle values, as shown in Figure 6. A residual friction angle of zero is assumed to eliminate any possible interlocking of the grains or blocks. A sensitivity analysis carried out for the specimens under tension showed no influence of this parameter in the response.

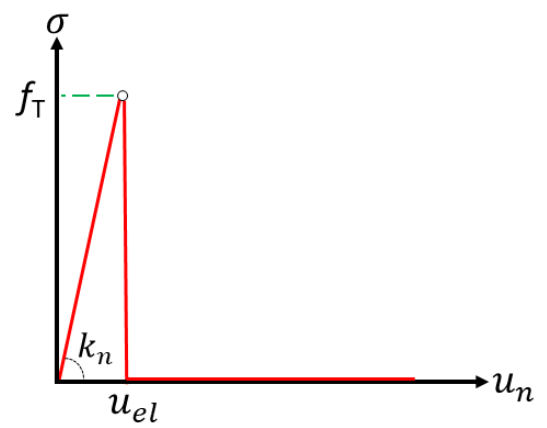

a) Tension cut-off (TC)

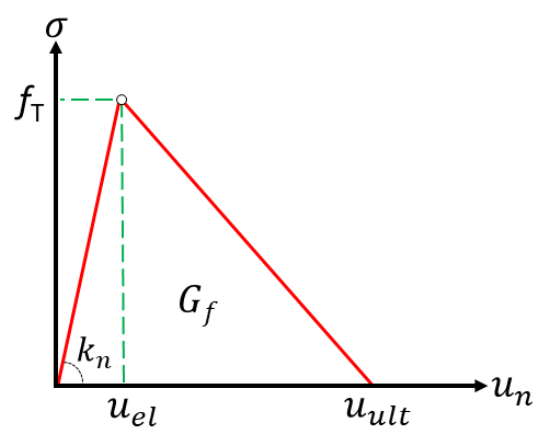

b) Linear softening (LS)

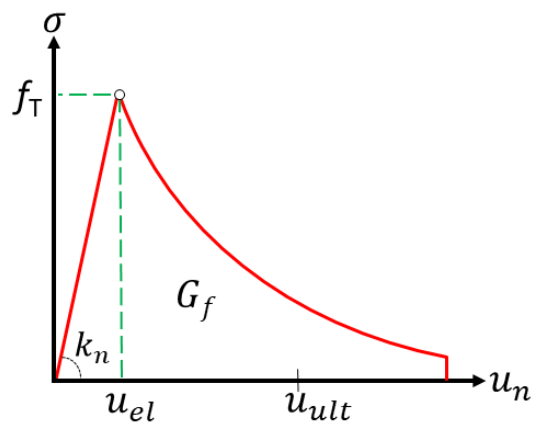

c) Polynomial softening (PS)

Figure 5. Contact constitutive models in tension; initial contact normal stiffness $\left(k_{n}\right)$.

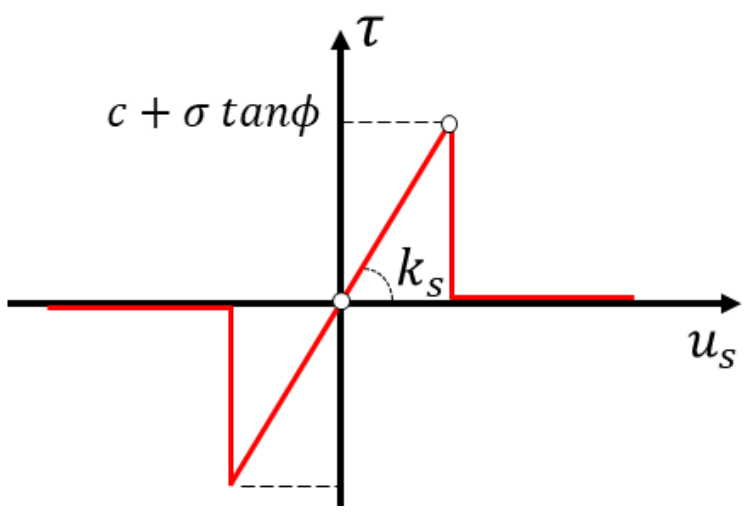

Figure 6. Coulomb-slip joint model; initial contact shear stiffness $\left(k_{s}\right)$, cohesion $(c)$ and friction angle $(\phi)$.

A simple ultimate normal displacement $\left(u_{u l t}\right)$ limit is imposed into the contact constitutive law based on the facture energy and the tensile strength of the material, given in Equation 12. 


$$
u_{u l t}=\frac{2 G_{f}}{f_{T}}
$$

Then, if the tensile failure occurs during the analysis, the tensile stresses are updated explicitly according to the proposed linear or polynomial softening models, presented in Equation 13 and 14 , respectively.

$$
\begin{gathered}
f_{t}=f_{T}\left(1+\frac{u_{c}-u_{e l}}{u_{e l}-u_{u l t}}\right) \\
f_{t}=f_{T}\left(\frac{u_{u l t}}{\left[u_{u l t}-\left(\frac{f_{T}}{k_{n}}\right)+u_{c}\right]}\right)^{\alpha}
\end{gathered}
$$

where $u_{c}$ indicates the current normal displacement. Note that the user defines the degree of the polynomial function $(\alpha)$, which should be arranged based on the fracture energy as well as the material behavior. Therefore, there is a stress update routine implemented into the explicit time integration scheme of the numerical procedure. However, it is important to note that there is no cyclic action considered in this study. Consequently, the proposed numerical models are only suitable for quasi-static analysis of quasi-brittle materials, such as concrete or masonry.

\subsection{Geometrical Representation of Concrete and Masonry Specimens}

The discontinuum models of the analyzed materials may vary depending on the desired level of accuracy and the resolution of the failure mode. Here, two different computational models are proposed to simulate complex fracture mechanism of plain concrete and brickwork assemblages. 


\subsubsection{Simplified Meso-Model (SMM)}

First, both concrete and masonry specimens are replicated via two discrete blocks with a smooth contact surface as shown in Figure 7. Deformation of the system is lumped at the joint, where there are sub-contacts at each gridpoint to simulate the mechanical interaction between the adjacent blocks. Relatively high elastic stiffness (i.e. 10 times more of macro elastic stiffness) is assigned for continuum blocks, denoted as semi-rigid, to control the governing deformation and nonlinear behavior of the numerical model only via discontinuity, since there is only one contact plane. It is worth noting that the proposed representation may be also considered as the simplest discontinuum model to capture the nonlinear response of the test specimens.

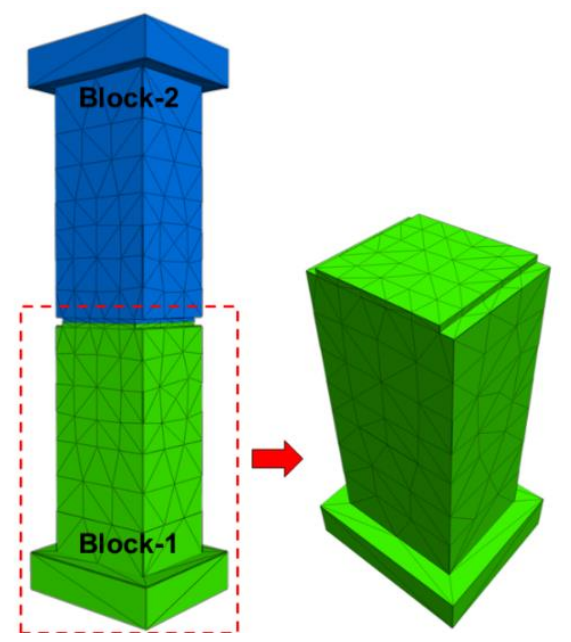

a) Double notched concrete specimen

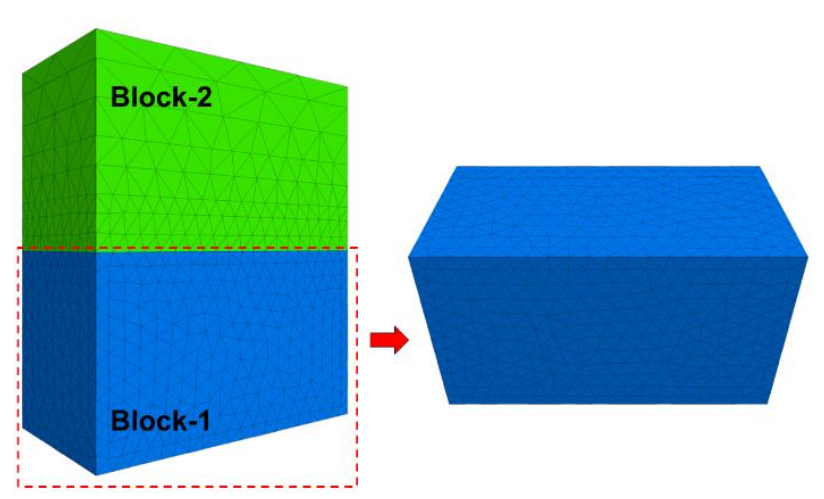

b) Stack bonded masonry prism

Figure 7. Simplified model of concrete and masonry prism, consisting of two separate blocks with a smooth contact surface.

\subsubsection{Detailed Meso-Model (DMM)}

In the detailed model, the internal structure of plain concrete and mortar are represented by a tessellation into polyhedral grains (or block) of controlled morphology (see Figure 8), as generated 
by the Neper software package (Quey et al. 2011; Quey and Renversade 2018). More specifically, a Laguerre tessellation is generated from weighted seed points, $S_{i}$, of coordinates $x_{i}$ and weight $w_{i}$, where a cell $\left(C_{i}\right)$, representing a block, is defined by Equation 15 .

$$
C_{i}=\left\{P_{i} \mid\left\|P_{i}-S_{i}\right\|^{2}-w_{i}<\left\|P_{i}-S_{i}\right\|^{2}-w_{i}\right\} \forall i \neq j
$$

The positions and weights of the seeds are optimized so as to obtain specified morphological properties of the cells (blocks). Here, the size and shape distributions are taken as those typically encountered in materials (Quey and Renversade 2018). The resulting tessellation is made of convex, polyhedral cells representing the adjacent blocks. In the deformation situation, these blocks interact through contact points at their boundaries. As the boundaries have roughly random spatial orientations, more realistic crack nucleation and propagation patterns are obtained compared to simplified model.

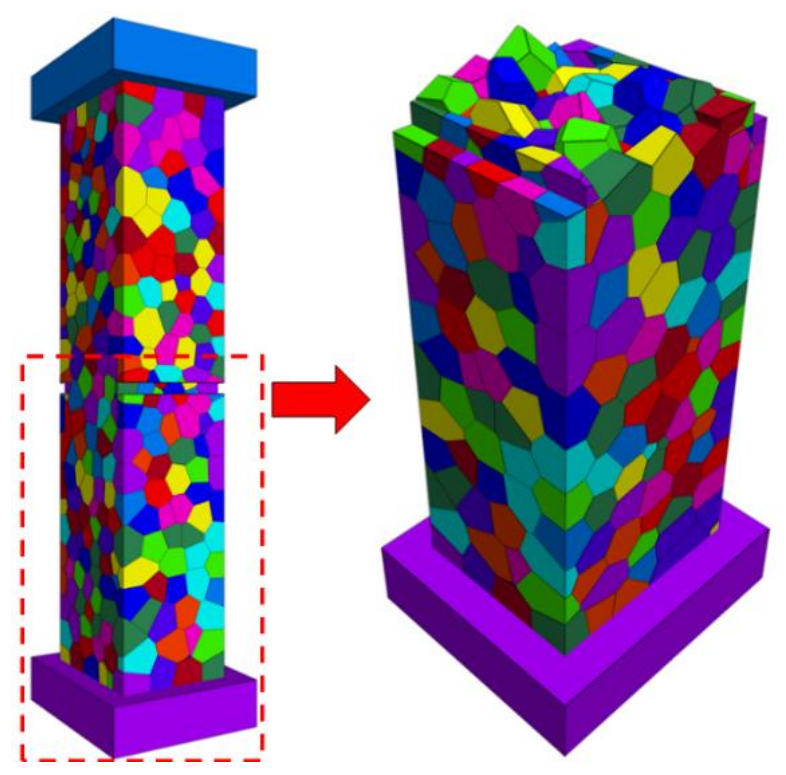

a) Double notched concrete specimen 


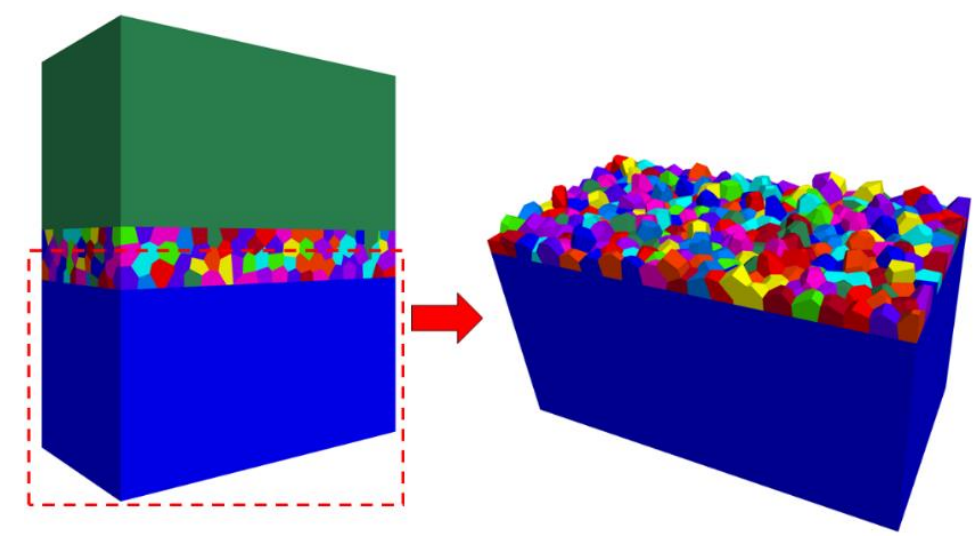

b) Stack bonded masonry prism

Figure 8. Representation of concrete and masonry prism specimens using a tessellation into polyhedral blocks.

\section{Tensile Behavior of Concrete Specimen: Discontinuum Analysis}

In order to trace the deflection of the concrete specimen, relative displacement (in the vertical direction) across the mid-length of the model (similar to the experimental setup) is recorded during the analysis. Furthermore, to eliminate the possible stress-concentrations between the steel plates and concrete specimen, polyhedral blocks are joined up-to a certain height, both at the bottom and top, as shown Figure 9. Then, the bottom plate of the specimen is fixed, and the self-weight is applied to obtain an initial state of equilibrium under gravity. Subsequently, the top middle gridpoint is subjected to a fixed velocity boundary condition by setting a displacement rate (velocity) of $0.5 \mathrm{~mm} / \mathrm{s}$ in the upward direction. Hence, the reaction forces are extracted at each time step via the implemented subroutine in the software, using FISH functions (an executable programming language in 3DEC). Furthermore, boundary conditions are adjusted according to the experimental setup; upper plate is kept rotatable but without distortion while bottom plate is fixed, similarly to (Rots and de Borst 1989). 


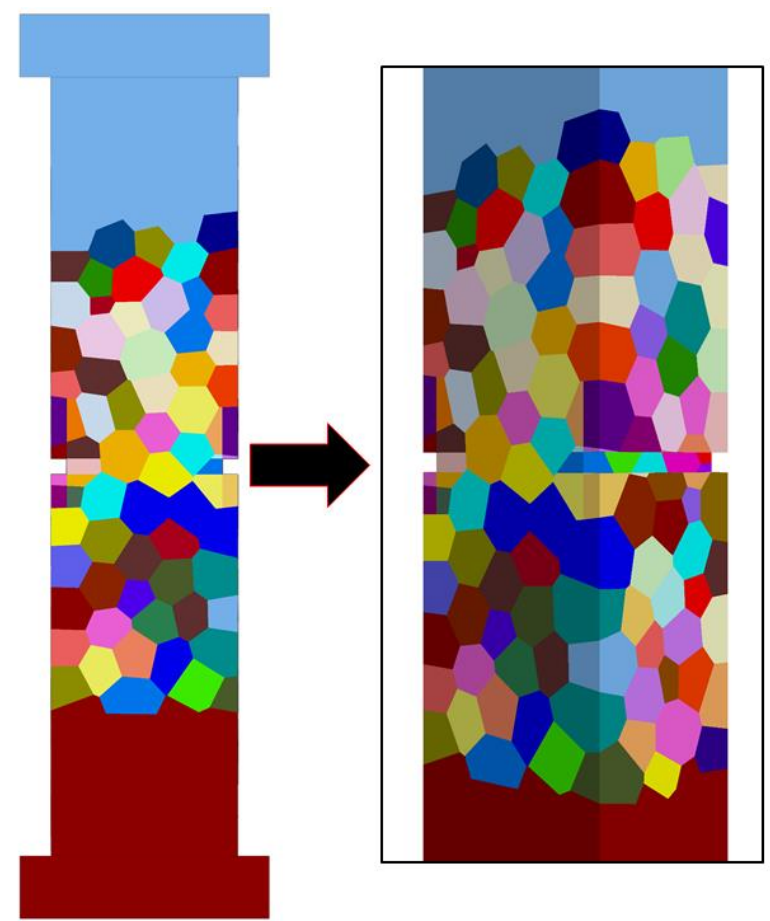

Figure 9. Representation of the detailed meso model: joined polyhedral blocks at the bottom and top and discrete polyhedral blocks in between.

\subsection{Macro- and Micro- Material Properties}

The elastic macro properties of the concrete specimens are assumed as $E=18 \mathrm{GPa}$ and $v=$ 0.2, taken from relevant research studies (Peerlings et al. 1998; Bobiński and Tejchman 2005). In detailed meso modeling, however, contact micro-parameters are required to simulate the mechanical interactions between blocks. Therefore, macro elastic properties (Young's modulus and Poisson's ratio) are used to predict contact stiffnesses in normal $\left(k_{n}\right)$ and shear $\left(k_{s}\right)$ directions using Equation 16 (Kazerani and Zhao 2010). 


$$
k_{n}=E / t, k_{s}=G / t
$$

where $t$ indicates the average thickness of the fracture zone. For instance, in fine meso-models, the average thickness is taken as $6 \mathrm{~mm}$, corresponding to 500 blocks (or grains). In the simplified meso model, the experimental stress-displacement curve is utilized to derive the elastic contact stiffness in the normal direction, which may also be estimated as the ratio of elastic modulus and the contact length in the absence of experimental data. The contact tensile strength $\left(f_{t}\right)$, is extracted from the experimental result as $3.25 \mathrm{MPa}$ and the fracture energy $\left(G_{f}\right)$ is set to $59.3 \mathrm{~J} / \mathrm{m}^{2}$, which is given in (Rots 1988; Hordijk 1991). The reference contact properties used for simplified and detailed meso models are presented in Table 1.

Table 1. Contact properties used in the two types of model. Contact properties - Simplified Meso Model

\begin{tabular}{|c|c|c|c|c|}
\hline$k_{n}(G P a / m)$ & $k_{S}(G P a / m)$ & $f_{T}(M P a)$ & $c(M P a)$ & $\phi\left(^{\circ}\right)$ \\
\hline 480 & 200 & 3.25 & 3.00 & 30 \\
\hline \multicolumn{5}{|c|}{ Contact properties - Detailed Meso Model } \\
\hline$k_{n}(G P a / m)$ & $k_{s}(G P a / m)$ & $f_{T}(M P a)$ & $c(M P a)$ & $\phi\left(^{\circ}\right)$ \\
\hline 3000 & 1250 & 3.25 & 3.00 & 30 \\
\hline
\end{tabular}

\subsection{Results of Simplified and Detailed Meso-Models}

In this section, the results of both simplified and detailed approaches are discussed by comparing their advantages and disadvantages in terms of simulating the material response and computational cost. 
First, the simplified model is tested to simulate the direct tension of the plain concrete specimen. There are three contact constitutive models used during the analysis. As expected, the tension cut-off yields abrupt stress drop as shown in Figure 10a. On the other hand, the linear and polynomial softening models provide better agreement with the experimentally obtained material response, where polynomial function, where $\alpha$ is taken as 3 as it provides the best result. Although the crack pattern at the contact surface cannot be obtained from the simplified analysis (since it is completely smooth), the model is quite efficient in terms of computational cost. Thus, the proposed simplified softening contact models can be employed in larger scale numerical models at structural level, such as beams or walls.

Then, the detailed model, made up of polyhedral blocks, is analyzed using the same fracture energy and three different contact models. There are 500 blocks used in the detailed model, providing acceptable resolution of cracking mechanism. The results of the analyses demonstrate that the contact constitutive model of tension cut-off not only neglects the post-peak behavior of the material but also underestimates the overall capacity for irregular geometries, generated by polyhedral blocks (Figure 10b). This phenomenon was also observed by others for the bending analysis of a concrete notched beam examined by simplified meso modeling technique (Resende et al. 2014). Furthermore, the linear and polynomial softening models show good agreement with the experimental data, both in terms of the ultimate load as well as the pre- and post-peak response of the material. 


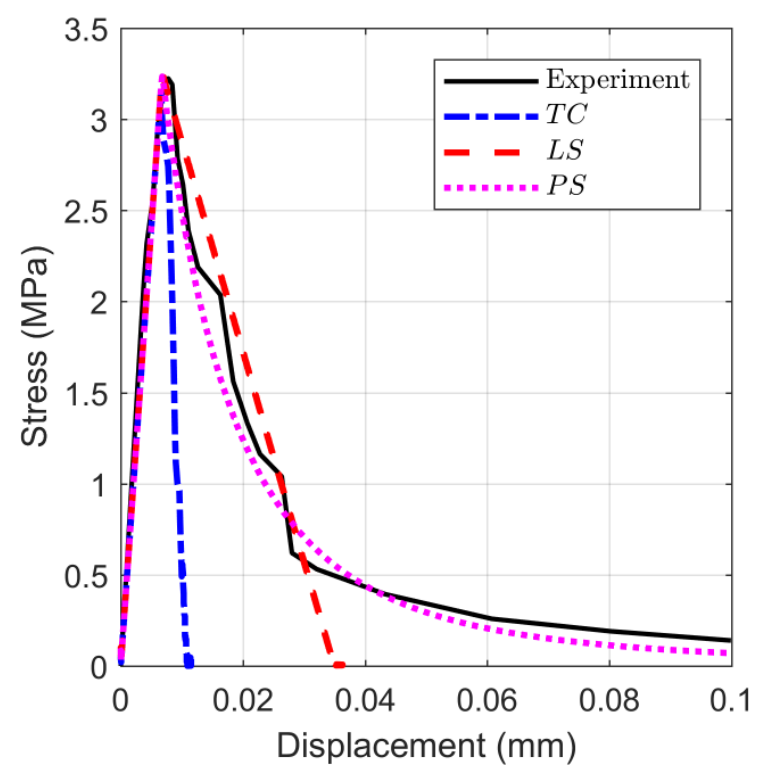

a) Simplified meso-model

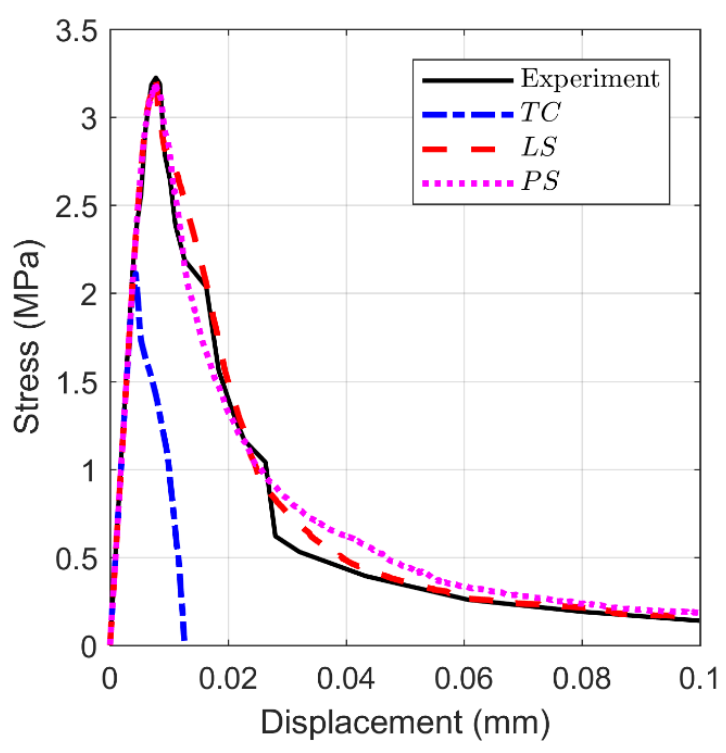

b) Detailed meso-model

Figure 10. Different tensile contact models compared with the experimental result (TC for tension cut-off, LS for linear softening and PS for polynomial softening)

In Figure 11, the two modeling approaches, simplified and detailed, are plotted in the same graph (polynomial softening is used as these are these are the best results for the simplified model). It can be clearly seen that pre-peak behavior of both numerical models and the ultimate tensile strength matched well with the experimental result. The softening branch of the detailed discrete element model slightly over estimates the post-peak response of the material toward the tail of the curve. 


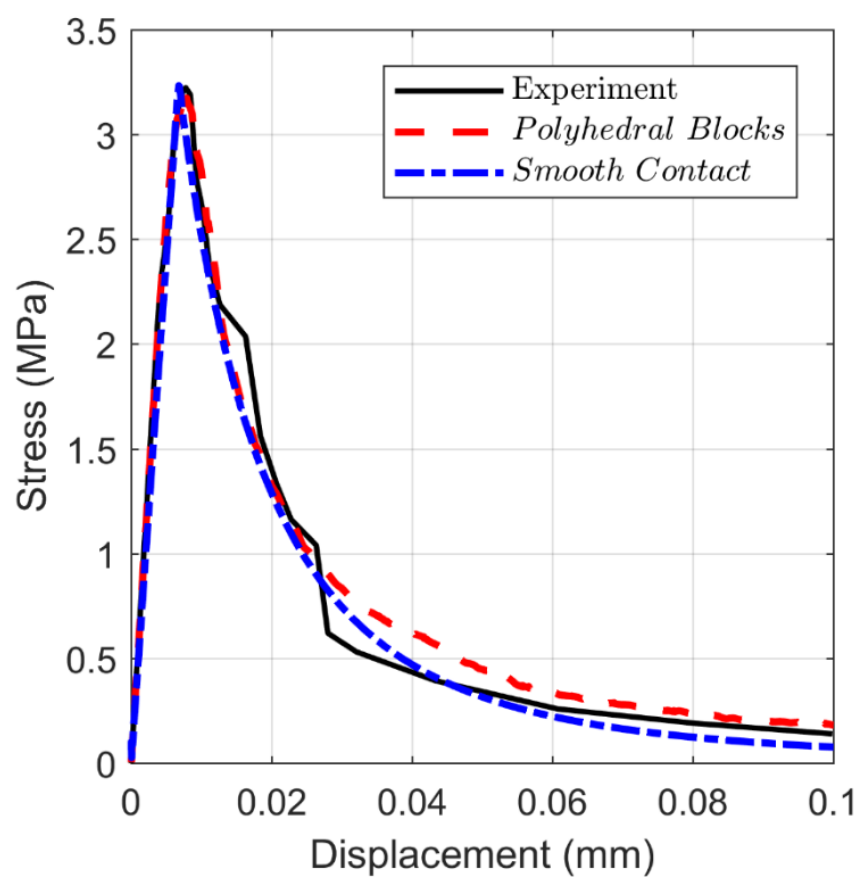

Figure 11. Comparison of experimental and numerical results (polynomial softening is shown).

\subsection{Sensitivity Analysis on the Contact Parameters using DMM}

A comprehensive set of sensitivity analyses is performed on the mechanical contact parameters, specifically cohesion, fracture energy, number (or size) of blocks and dilation angle. Reference properties employed throughout the parametric analyses are given in Table 2.

Table 2. Reference contact and material properties.

\begin{tabular}{ccccc}
$f_{T}(M P a)$ & $c(M P a)$ & $\psi\left({ }^{\circ}\right)$ & $G_{f}(N / m)$ & Number of blocks \\
\hline 3.25 & 3.00 & 0 & 59.3 & 500
\end{tabular}

Cohesion: The influence of cohesion, being activated by shear forces along the joints, is examined varying from $0.75 f_{t}$ to $2.00 f_{t}$. It is observed that discrete element model is quite sensitive to the cohesion parameter when it is less than the tensile strength $\left(c<f_{T}\right)$ as shown in 
Figure 12. Conversely, higher cohesion values $\left(c>f_{T}\right)$ do not contribute to the tensile strength remarkably, however, it influences post-peak response (softening regime). This sensitivity originates from the disordered internal structure of the numerical model where the shear stresses develop at the interlocking surface planes among the blocks and vary the macro behavior. Thus, in the case of lack of data, adopting the cohesion strength equal to 1.5 times the tensile strength of the material may provide acceptable accuracy from the discontinuum analysis, which is also proposed by (Lourenço 1996; Pina-Henriques and Lourenço 2006).

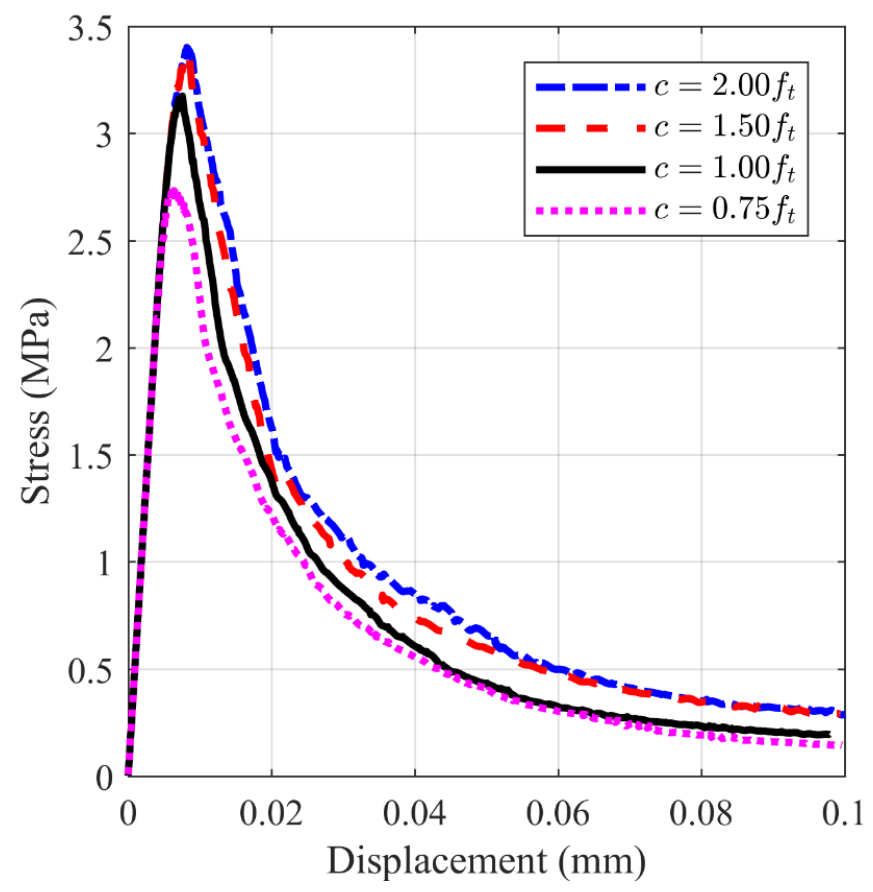

Figure 12. Influence of cohesion $(c)$ on the stress-displacement response of the discrete element model.

Fracture Energy: The fracture energy is varied between 20 to $80 \mathrm{~N} / \mathrm{m}$. Results show that lower fracture energy (or energy dissipation through the plastic deformation) causes more brittle 
material response and underestimates the tensile strength (Figure 13). Although this behavior is expected, it is worth noting that there is no drastic change observed unless the assigned fracture energy is less than half of the reference value of $f_{t}=59.3 \mathrm{~N} / \mathrm{m}$. Furthermore, influence of the higher values of fracture energy (i.e. $f_{t}=80.0 \mathrm{~N} / \mathrm{m}$ ) is observed mainly in the post-peak response of the material.

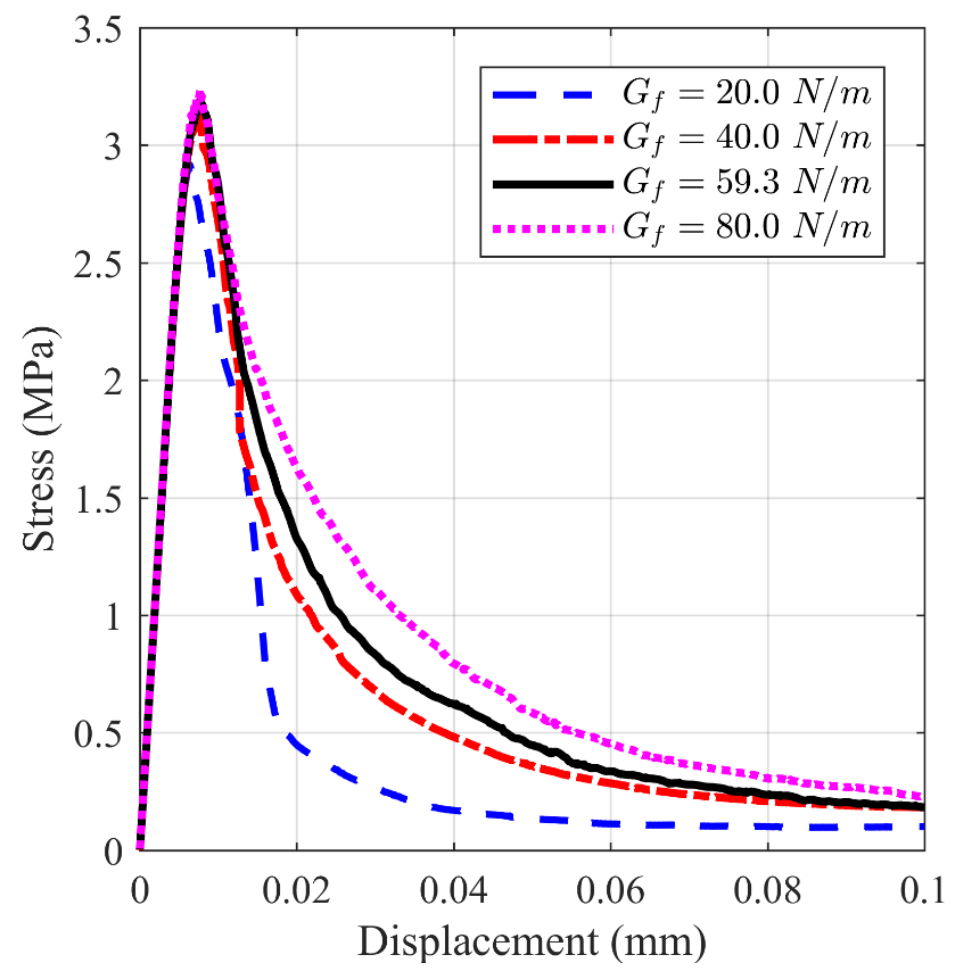

Figure 13. Influence of fracture energy $\left(G_{f}\right)$ on the stress-displacement response of the discrete element model.

Number of Blocks: Discrete element codes, such as 3DEC, adopt point contact hypothesis. However, this simplifies the representation of real contact and does not always provide accurate stress distributions along the discontinuities unless a large number of contact points are utilized (Lemos 2016). Therefore, it is necessary to employ an adequate number of contact points to better 
evaluate the stress distributions at the contact surfaces and represent the cracking mechanism accurately. In the present research, influence of the number of polyhedral blocks (or grain number) is investigated considering different fracture energies, shown in Figure 14. The results of the analyses indicate that the proposed contact model, provides similar results without a strong dependency on the number of blocks.

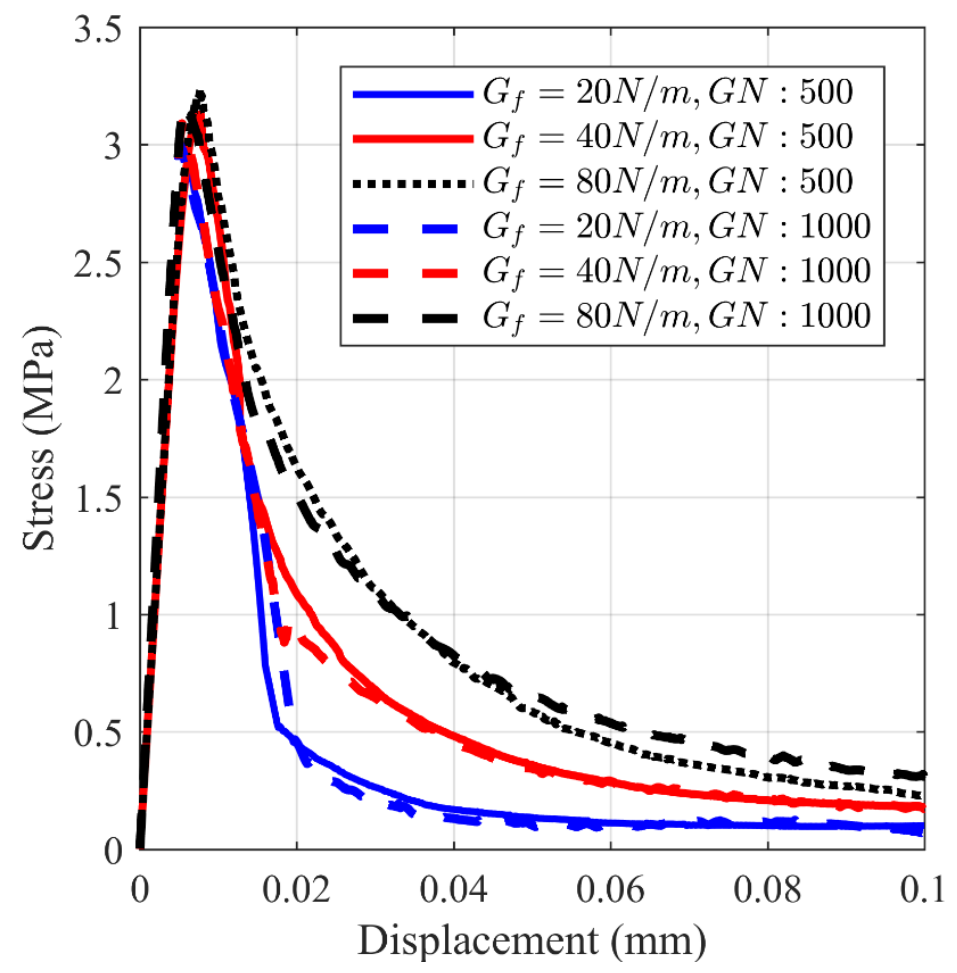

Figure 14. Influence of the grain number $(\mathrm{GN})$ on the macro behavior for different fracture energies.

Dilation: Additionally, the effect of dilation angle is investigated varying from $0^{\circ}$ to $30^{\circ}$. It is noted that joint dilation angle does not cause a significant change on the macro behavior of the discrete element model, if it is considered less than one third of friction angle under uniaxial tensile forces (Figure 15). On the other hand, unfavorable influence of higher dilation angle is 
observed, as in the case of associated flow $(\psi=\phi)$, which shifts significantly from the experimentally obtained softening behavior. Thus, associated flow should not be used in this type of analysis.

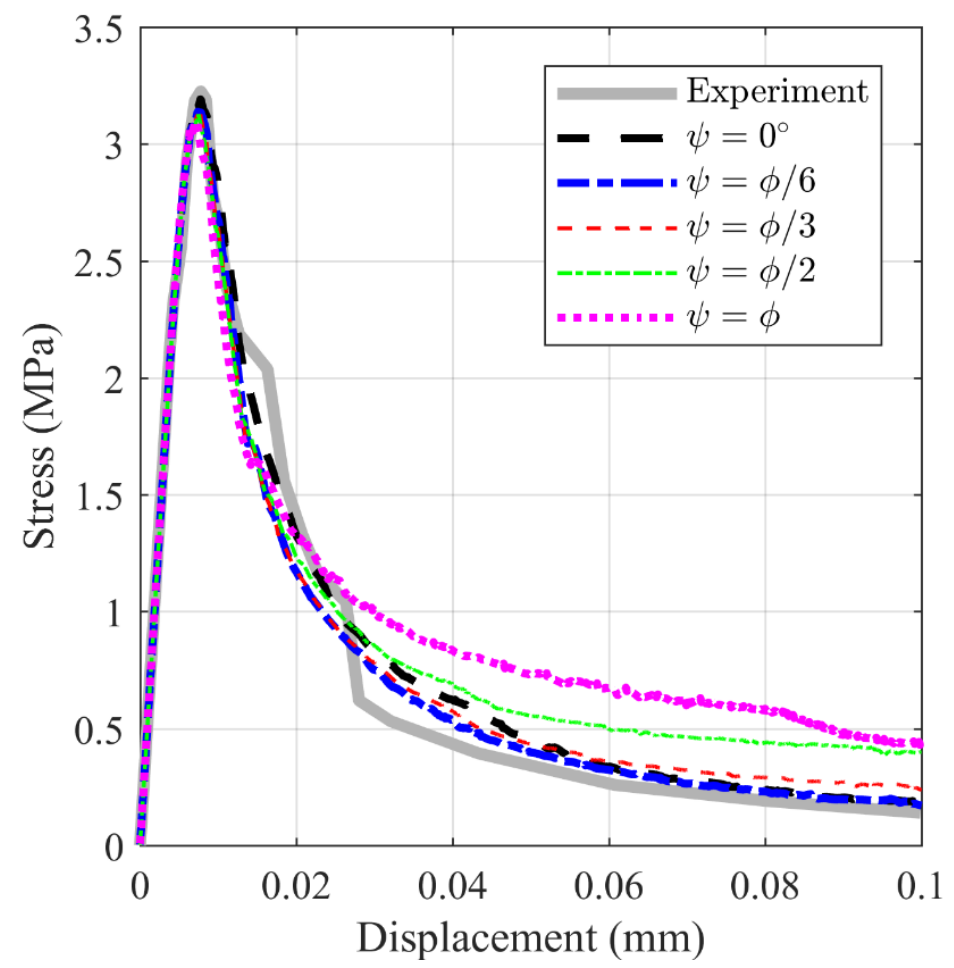

Figure 15. Influence of the dilation $(\psi)$ on the stress-displacement response of discrete element model.

\subsection{Prediction of the Fracture Mechanism}

The boundary conditions are examined using reference properties. Notwithstanding that direct tension tests are quite difficult to perform compared to indirect methods. Attachment of the specimens to the steel platens and achieving proper (if possible perfect) alignment of the specimen requires utmost attention to avoid secondary bending moments at the supports affecting the 
fracture mechanism and energy dissipation. There are also other issues influencing the strength and fracture energy of concrete subjected to uniaxial tension, such as environmental factors and scale of the specimen (van Mier and van Vliet 2002). All these aspects are the key components to obtain stable softening behavior from the experiment.

In short, the softening regime and consequently the fracture energy of the material directly depend on the boundary conditions. Two experimental setups are considered here to observe the change in the material response using detailed meso models, rotatable (pinned) and fixed end platens (nonrotatable), represented in Figure 16b. The difference in the material response is confirmed via DMM as shown in Figure 16a where the fixed boundary condition yields mild softening behavior compared to pinned boundary condition with more complex cracking behavior.

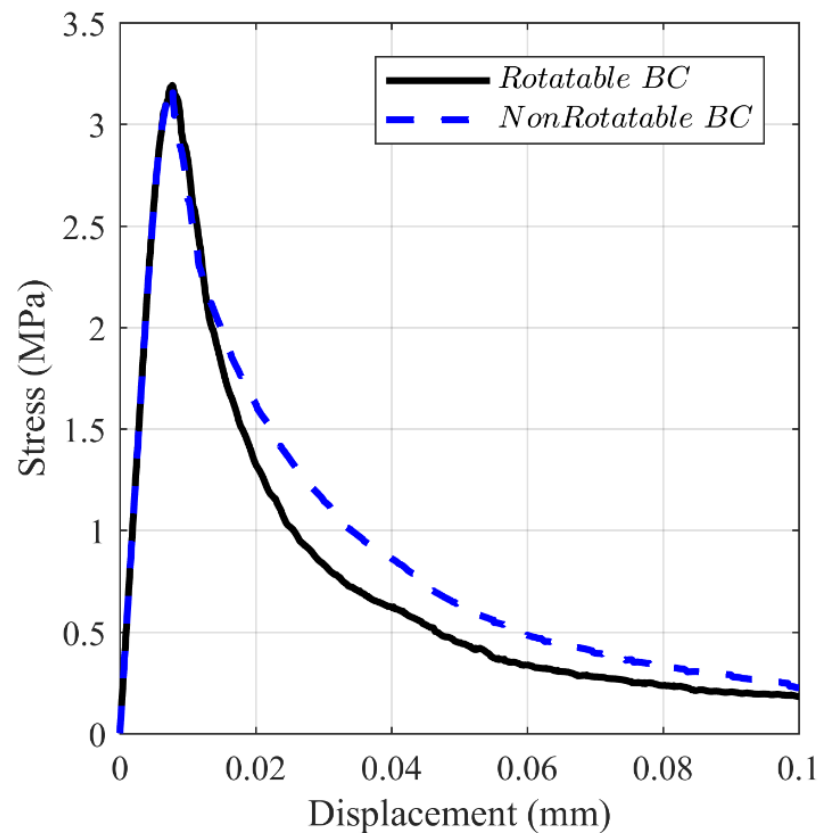

a) Influence of the boundary conditions on the response of the concrete specimen.
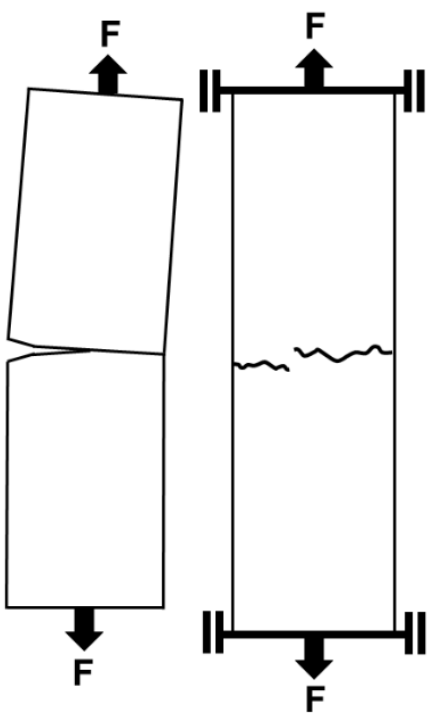

b) Left: Rotatable boundary condition; Right: Nonrotatable boundary conditions.

Figure 16. Influence of boundary conditions. 
During the analysis, the non-uniform cracking mechanism is traced to better understand the failure process of the plain concrete specimen under uniaxial tension. In case of rotatable boundary condition, at the onset of the macrocrack, there is no restraints imposed on the specimen and crack propagates from one side of the specimen to the other. This fracture mechanism yields a non-homogenous cracking pattern, which is successfully demonstrated via the detailed model, given in Figure 17. Furthermore, it is worth noting that the examined fracture mechanism is inherently a three-dimensional process, hence, the cracks also propagate from the front face to the back of the specimen (or vice versa). As a result, fracture lines obtained via 2D models are unable to replicate the complex 3D reality of both faces of the specimen. 


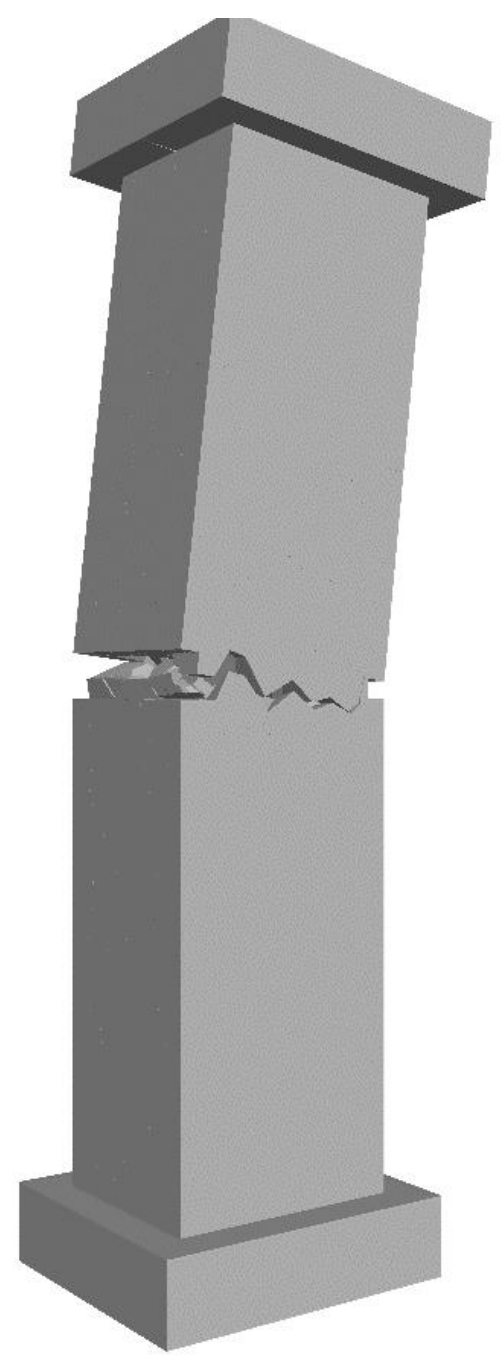

a) Macro behavior of the specimen

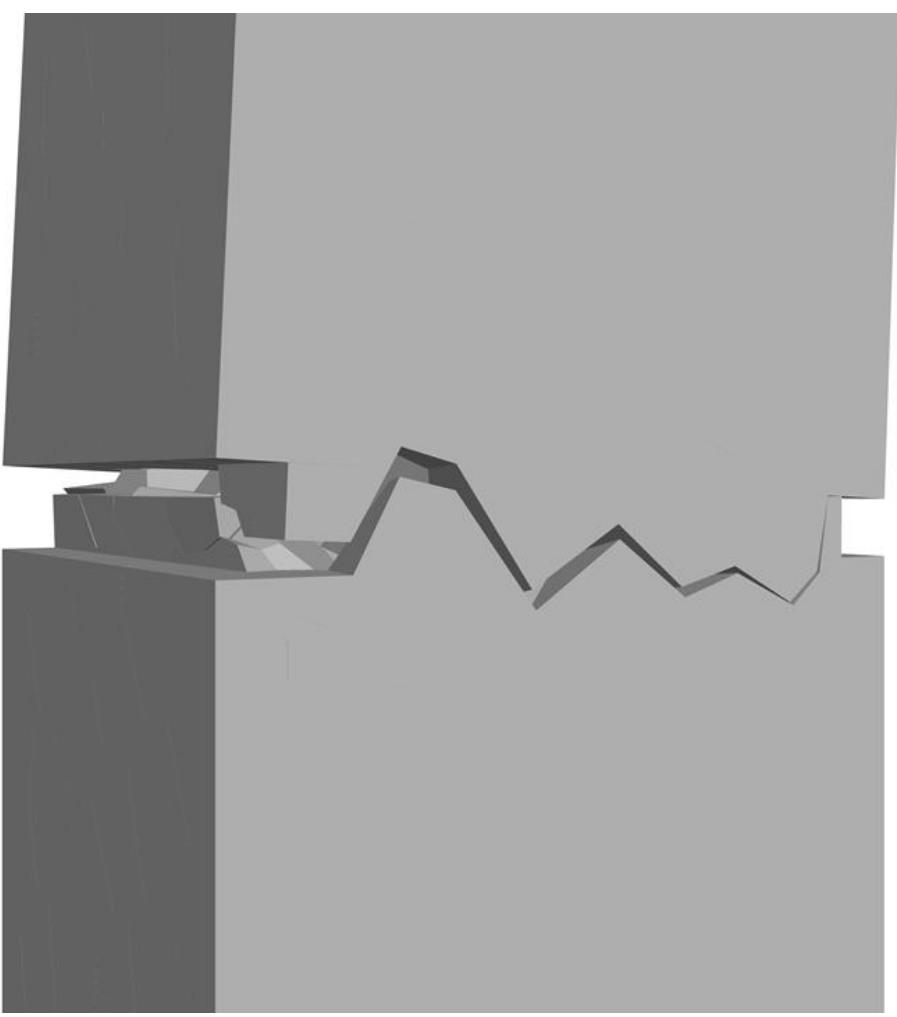

b) Nonuniform crack propagation; from left to right

Figure 17. Failure mechanism of a notched concrete specimen under direct tension (rotatable boundary condition).

In fixed (or clamped) end conditions, the eccentricity caused by the nonuniform crack openings is balanced at the boundaries developing bending moments (Vasconcelos 2005). This may result in multiple cracks once the tensile strength is reached. Again, the phenomenon is captured through the discontinuum analysis as shown in Figure 18, in which the front and back 
faces have rather different visible crack patterns. Thus, a more complex fracture surface is obtained compared to pinned boundary conditions.
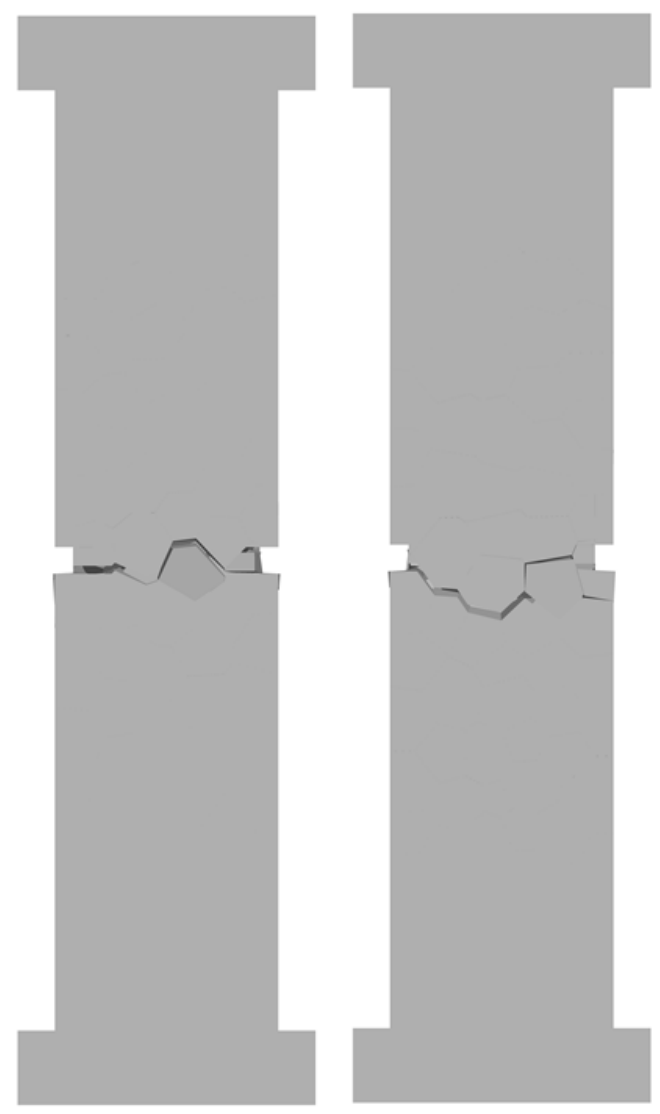

a) Left: Front face; Right: Back face b) Cracked surface of the specimen at the complete failure

Figure 18. Failure mechanism of a notched concrete specimen under direct tension (fixed boundary condition).

\subsection{Investigations on the Mixed Fracture Mode in Concrete}

The proposed numerical modeling strategy is further applied to a concrete beam for the simulation of the mixed mode crack propagation. In order to validate the computational model, an 
experimental investigation presented by (Gálvez et al. 1999) is taken into consideration as a benchmark study. The results given in the reference work are utilized to compare the detailed meso models predicting the force-displacement behavior of the material as well as the crack trajectory. Note that the three-point beam bending problem from the reference study is analyzed here.

The softening contact constitutive law (polynomial) in the normal direction and Coulombslip joint model in shear are used during the analyses. The identical geometrical configuration (Figure 19), test setup (boundary conditions) and material properties are adopted in the discrete element model that are given in (Gálvez et al. 1999). Different number of blocks (500, 750 and 1000) are used and contact stiffnesses are estimated based on the average thickness of the fracture zone as mentioned earlier. Material and contact properties can be found in Table 3.

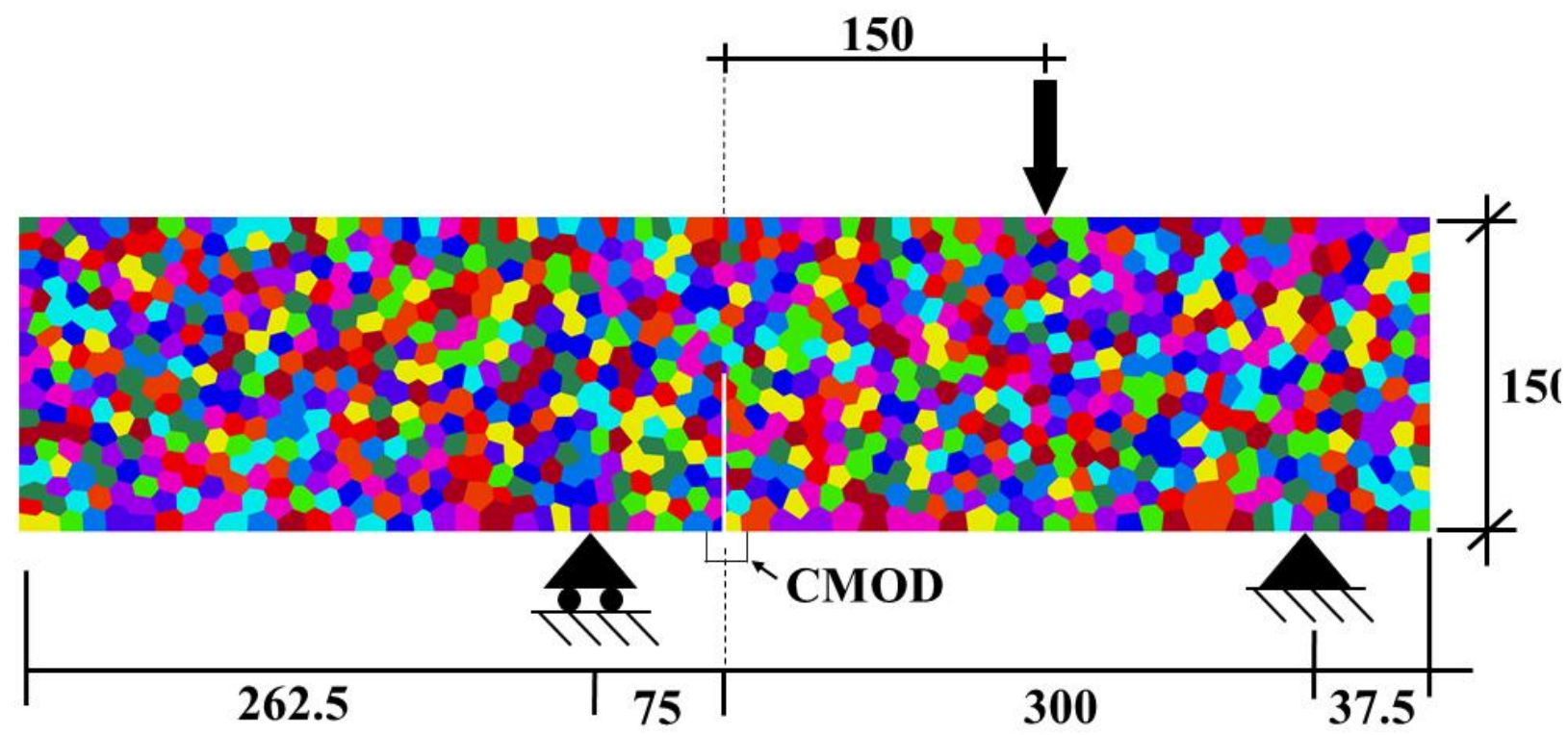

Figure 19. Mixed-mode three point bending test setup given in (Gálvez et al. 1999), dimensions are in $\mathrm{mm}$. 
Table 3. Material and contact properties (contact stiffnesses are given for 500, 750 and 1000 blocks, respectively).

\begin{tabular}{|c|l|}
\hline$E(G P a)$ & 38 \\
\hline$v$ & 0.2 \\
\hline$k_{n}(G P a / m)$ & $3800,3400,2750$ \\
\hline$k_{s}(G P a / m)$ & $1580,1470,1150$ \\
\hline$f_{T}(\mathrm{MPa})$ & 3.0 \\
\hline$c(\mathrm{MPa})$ & $1.5 f_{T}$ \\
\hline$\phi\left(^{\circ}\right)$ & 30 \\
\hline$G_{f}^{I}(\mathrm{~N} / \mathrm{m})$ & 59.3 \\
\hline
\end{tabular}

Figure 20 shows the load vs. CMOD curves for different number blocks where similar preand post-peak behaviors can be observed. Furthermore, similar cracking pattern is obtained from the numerical model as presented in Figure 21, which is in line with the experimentally found path envelope. It is worth noting that application of the solely mode I fracture energy provides reliable results to examine the mixed mode fracture, which is also confirmed by (Bocca et al. 1990).

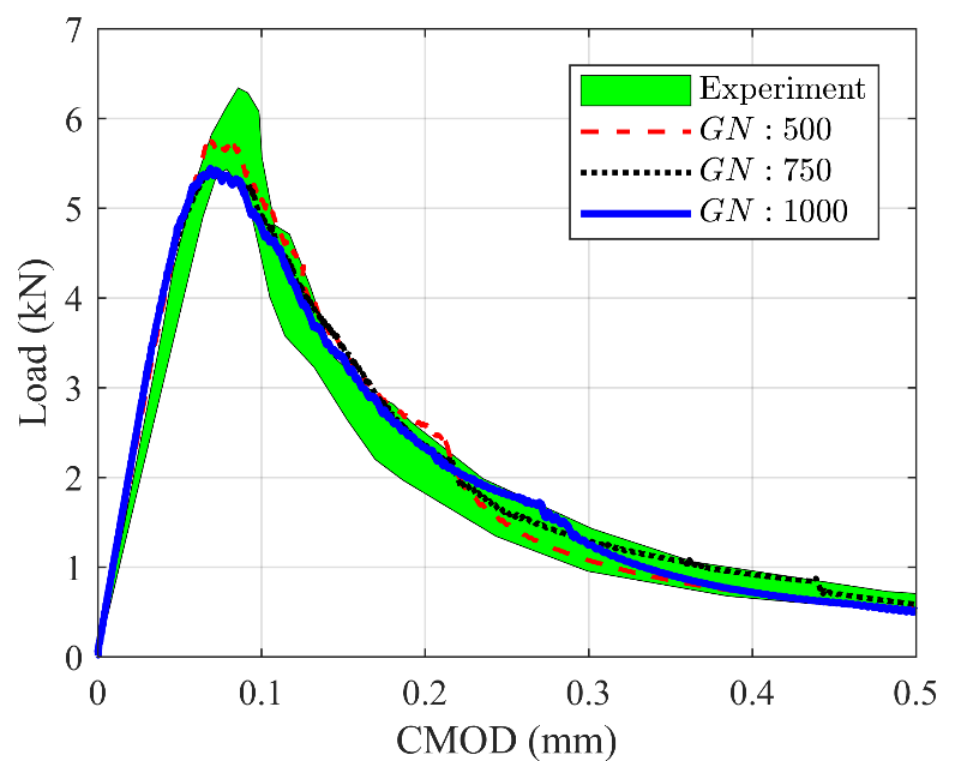

Figure 20. Force vs CMOD response of the concrete beam considering different number of blocks (or grain numbers, $G N$ ). 


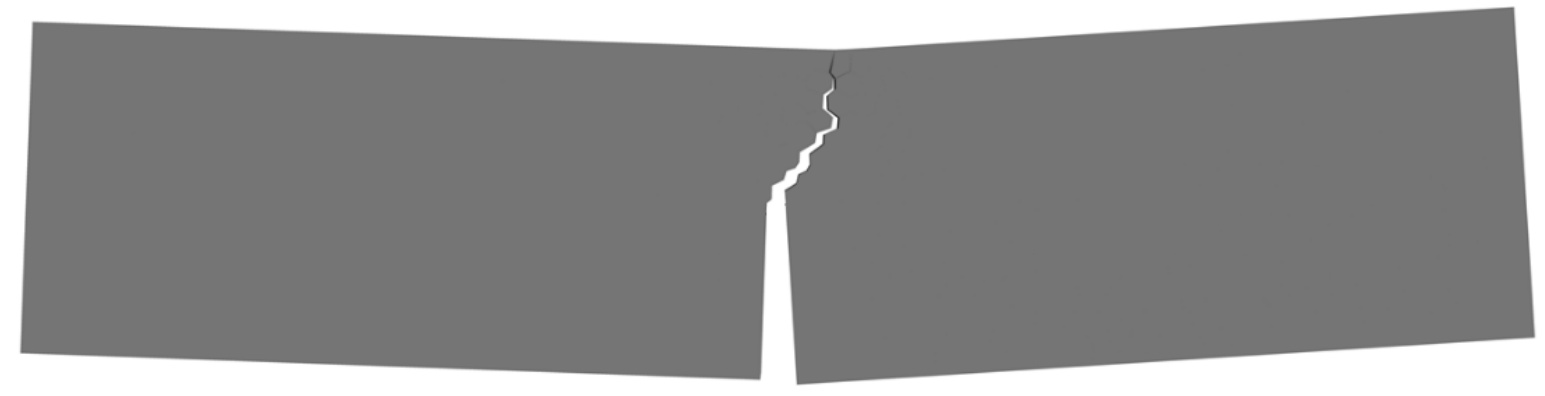

a) Cracked shape of the concrete beam under three-point bending.

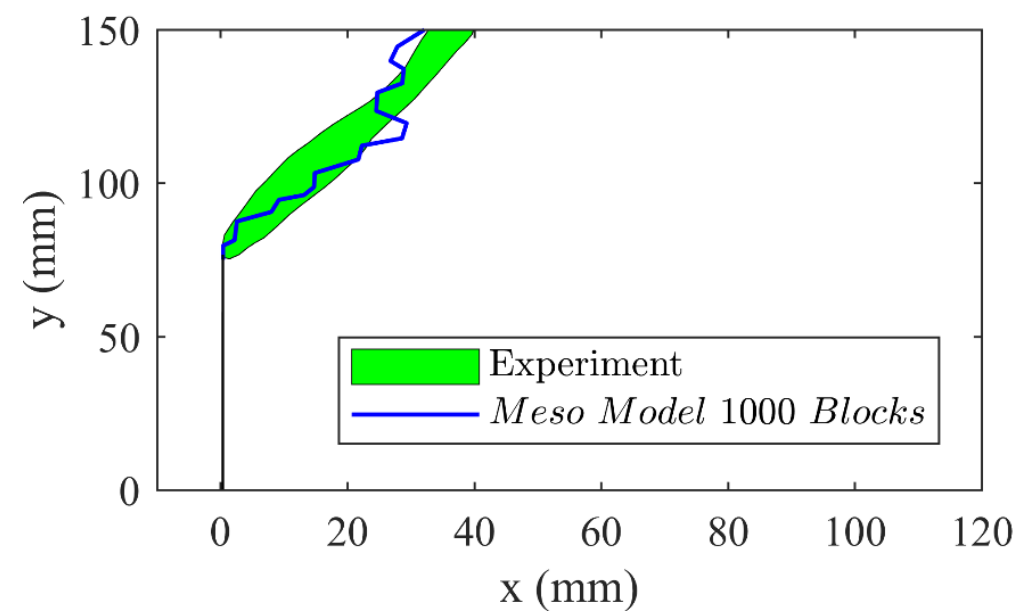

b) Comparison between the experimental and numerical crack trajectories.

Figure 21. Mixed fracture mode obtained via detailed meso-model (100 blocks) and the experimental envelope.

\section{Discontinuum Analysis of the Tensile Behavior of Masonry Prism}

In this part of the article, the fracture mechanism of a stack bonded masonry prism under direct tensile forces is numerically investigated. The same modeling strategies, performed on the concrete specimen, are followed to predict the strength and cracking mechanism of a masonry prism. Fixed boundary conditions are utilized to replicate the reference experimental study and only the polynomial contact softening model is used throughout the analyses, since it provides better approximations as discussed earlier. 
Masonry is a composite and heterogeneous material, consisting of units and mortar. It can be built with a single material (i.e. dry-joint) or a mixture of materials. Clay bricks, concrete blocks, stone, adobes are common examples of masonry units, whereas mortar is a mixture of sand, water and a binder such as cement or lime. Thus, it is self-evident that the mechanical response of masonry is governed by the individual behaviour of each ingredient as well as the interaction between them. However, if there is no reinforcement, masonry assemblages have very low tensile strength compared to their compression capacity, similar to plain concrete. Additionally, there are various factors that may influence the mechanical bond between the unit and mortar, such as surface porosity, roughness of the substrate as well as the aggregate water content among others (Adami and Vintzileou 2008). In this article, three failure modes of masonry prisms, experimentally observed by (Vintzileou and Adami 2009), are investigated via detailed meso models to better understand the tensile fracture mechanism of stack bonded masonry prisms. All possible failure modes are considered at the bond between the unit-mortar interface and/or in mortar, shown in Figure 22.
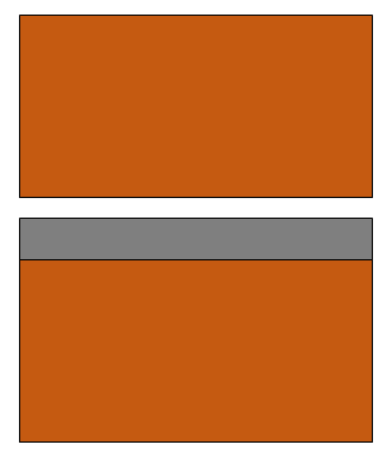

a) Mode-A: Interface failure

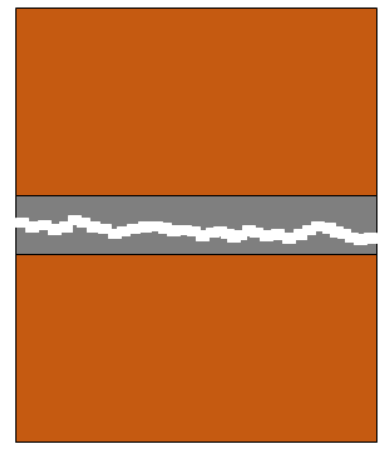

b) Mode-B: Cracking in mortar

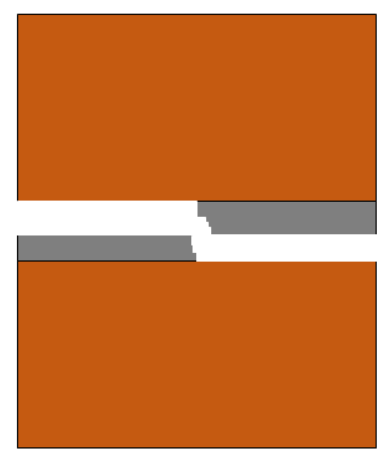

c) Mode-C: Partial failure of mortar

Figure 22. Failure modes of stack bonded masonry prisms under uniaxial tension test. 


\subsection{Material and Contact Properties}

Contact parameters are calculated based on the macro-elastic properties $(E, v)$, given in (Van der Pluijm 1997), for both simplified and detailed meso models that are shown in Table 4 and Table 5, respectively. The contact stiffness $\left(k_{n}\right)$ of the simplified model is estimated as $E_{\text {mortar }} / t_{\text {mortar }}$

Table 4. Contact properties used in the simplified meso model.

\begin{tabular}{cccccc}
\hline$k_{n}(\mathrm{GPa} / \mathrm{m})$ & $k_{s}(\mathrm{GPa} / \mathrm{m})$ & $f_{T}(\mathrm{MPa})$ & $c(\mathrm{MPa})$ & $\phi\left(^{\circ}\right)$ & $G_{f}(\mathrm{~N} / \mathrm{m})$ \\
\hline 200 & 80 & 0.40 & 0.40 & 38 & 10
\end{tabular}

Furthermore, micro-contact stiffnesses are predicted based on thickness of the fracture zone as given previously in Equation 16. The average thickness of fracture zone is taken as $5 \mathrm{~mm}$ and $4 \mathrm{~mm}$, corresponding to 500 and 1000 blocks. (or grains), respectively. Finally, the tensile strength of the mortar is assumed as $10 \%$ of its compression strength and fracture energy (modeI) is approximately estimated based on the reference experimental study. Again, relatively high elastic stiffness (10 times of macro elastic stiffnesses) is utilized for polyhedral and continuum blocks to control the governing deformation and nonlinear behavior of the numerical model via discontinuities.

Table 5. Reference contact properties used in the detailed meso model.

Mortar-Unit Interface

\begin{tabular}{cccccc}
\hline$k_{n}(\mathrm{GPa} / \mathrm{m})$ & $k_{s}(\mathrm{GPa} / \mathrm{m})$ & $f_{T}(\mathrm{MPa})$ & $c(\mathrm{MPa})$ & $\phi\left(^{\circ}\right)$ & $G_{f}(\mathrm{~N} / \mathrm{m})$ \\
\hline 600 & 250 & 0.40 & 0.40 & 38 & 10 \\
& & Mortar-Mortar Interaction & & \\
\hline$k_{n}(\mathrm{GPa} / \mathrm{m})$ & $k_{s}(\mathrm{GPa} / \mathrm{m})$ & $f_{T}(\mathrm{MPa})$ & $c(\mathrm{MPa})$ & $\phi\left(^{\circ}\right)$ & $G_{f}(\mathrm{~N} / \mathrm{m})$ \\
\hline 600 & 250 & 0.80 & 0.80 & 38 & 20
\end{tabular}




\subsection{Prediction of Failure Mode for Masonry Assemblages under Direct Tension}

First, the simplified and detailed models are compared with the experimental results, shown as an envelope in Figure 23. The results indicate that both approaches provide similar results in pre- and post- peak regime. Since the mortar-unit interface has less tensile strength than the mortar joint, the failure occurred at the interface indicating a tensile strength of $0.4 \mathrm{MPa}$. It is important to note that the results obtained from the simplified approach, requiring less computational effort, are in line with the detailed model and may be preferable for large scale masonry structures, such as walls and columns.

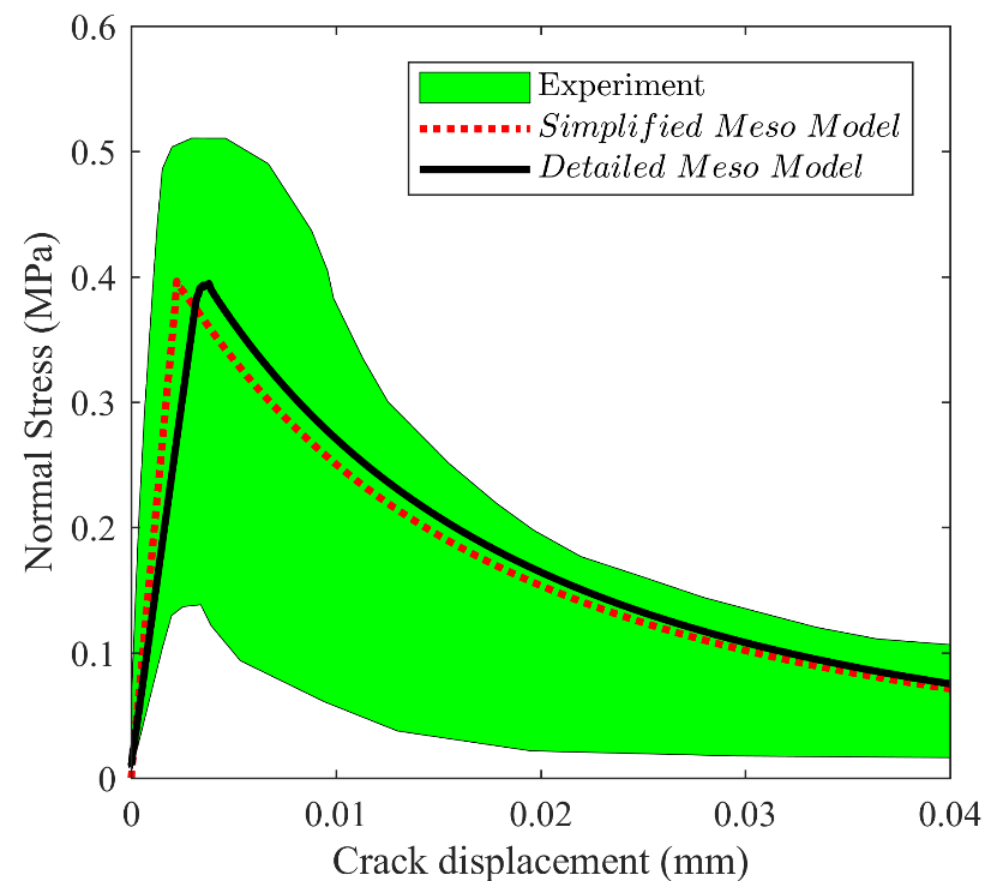

Figure 23. Macro behavior of the simplified and detailed meso models.

On the other hand, when the tensile strength of mortar is different from the interface, the governing failure mechanism and capacity are controlled by the weaker one, as expected. The 
obtained stress-displacement curves for weak and strong mortar scenarios are given in Figure 24. This is demonstrated using the detailed model, where weak mortar, i.e. $\left(f_{t}\right)_{\text {mortar }}=0.2 M P a$, results in lower overall capacity together with the failure mode-B (Figure 25a), while strong mortar, i.e. $\left(f_{t}\right)_{\text {mortar }}=0.8 \mathrm{MPa}$, causes interface failure corresponding to failure mode-A (Figure 25b).

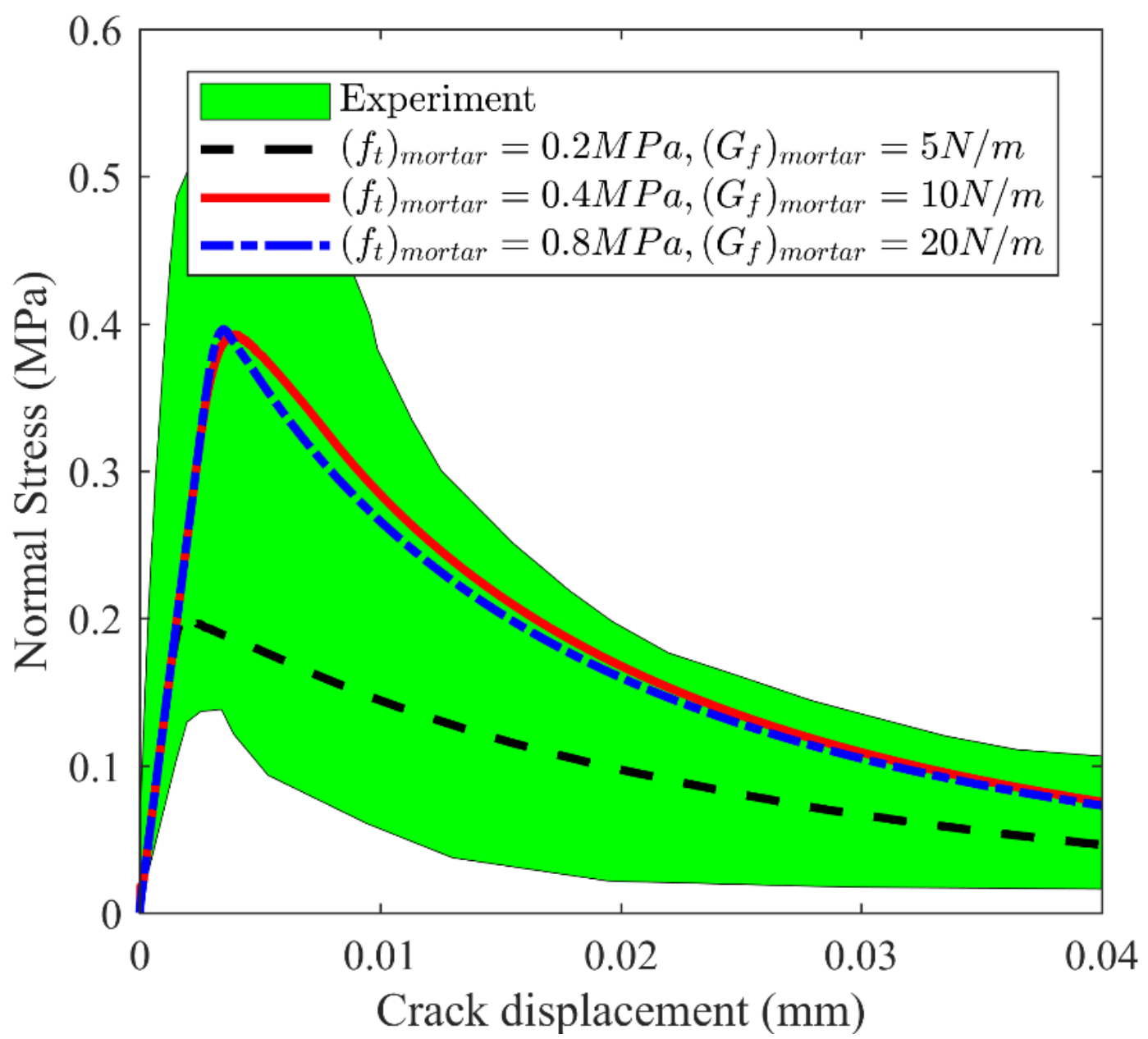

Figure 24. Influence of weak and strong mortar on the macro behavior of masonry prism specimens; $\left(f_{t}\right)_{\text {interface }}=0.4 \mathrm{MPa},\left(G_{f}\right)_{\text {interface }}=10 \mathrm{~N} / \mathrm{m}$. 


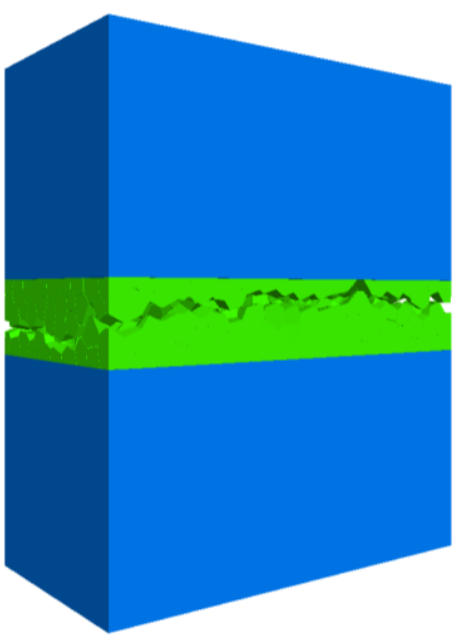

a) Cracking in mortar (Mode-B).

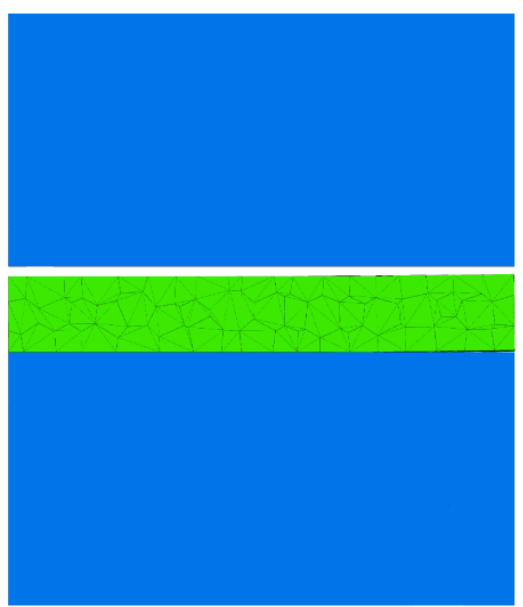

b) Unit-mortar interface failure (Mode-A)

Figure 25. Detailed meso-model; Continuum Blocks (Masonry Units) and Discrete Polyhedral Blocks (Mortar).

In addition, the influence of the number of grains $(\mathrm{GN})$ and the fracture energy $\left(G_{f}\right)$ are explored using the detailed meso model. During the analyses, an identical tensile strength at the mortar and unit-mortar interface is used. In Figure 26, the results for various combinations of mortar and unit-mortar interface properties with respect to number of grains are given. It has been observed that when mortar is more brittle (i.e. $\left(G_{f}\right)_{\text {mortar }} \leq\left(G_{f}\right)_{\text {interface }}$ ), the failure mechanism is controlled by mortar (Mode-B or Mode-C) rather than the interface. In Figure 27, a typical partial detachment of mortar is presented. Furthermore, there is no significant change noted in stress-displacement curves and failure mechanisms for different grain sizes (or number of blocks), which provides computational mesh size independency. 


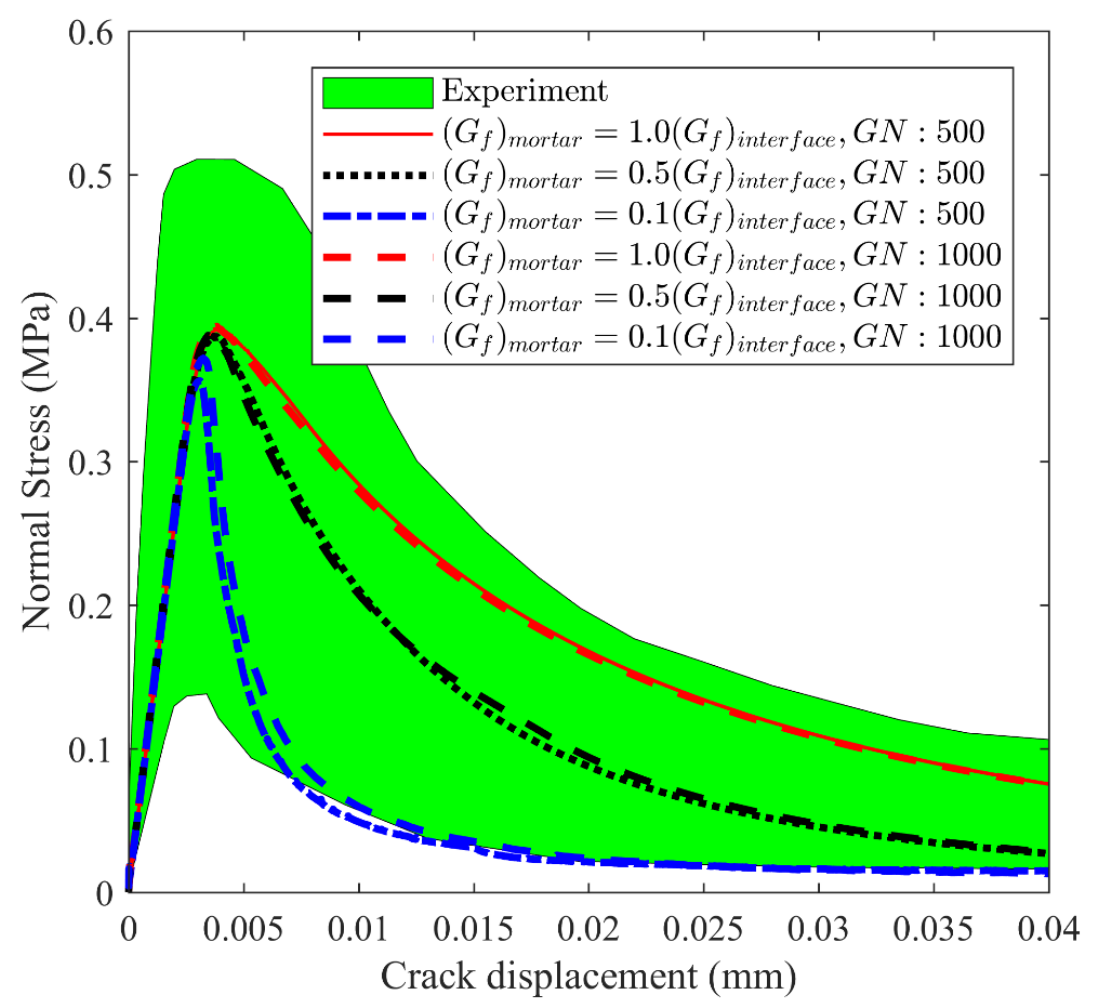

Figure 26. Parametric analysis on the detailed meso model $\left(\left(f_{t}\right)_{\text {mortar }}=\left(f_{t}\right)_{\text {interface }}\right)$.
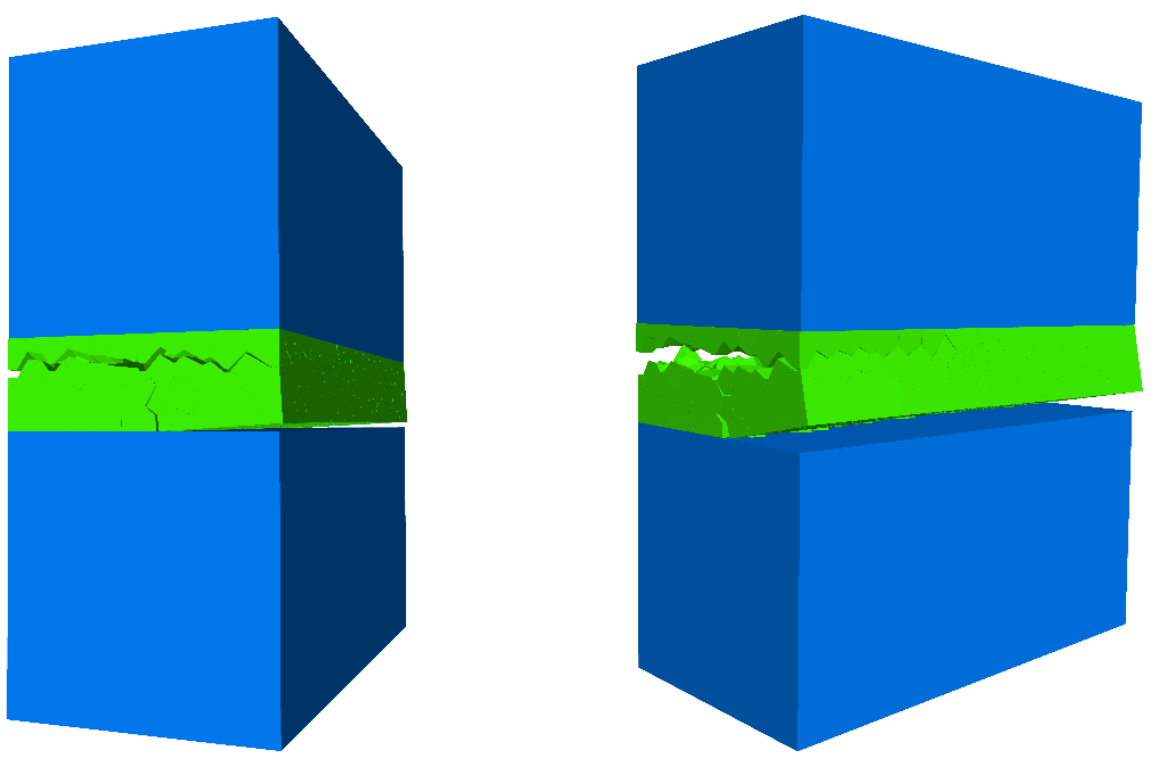

Figure 27. Partial failure of mortar obtained via detailed meso model. 


\subsection{Mixed-Mode Fracture of Brickwork Assemblages}

In this part, the proposed tensile softening contact model (polynomial) is utilized in brickwork assemblages to investigate the mixed fracture mode in a masonry panel represented via the simplified meso model. It is aimed to present the applicability of the computational modeling strategy on the masonry panel tests as well as the simulation of the complex cracking mechanism in masonry. To achieve this goal, three point beam bending experiment performed by (Reyes et al. 2008), is used to validate the numerical model considering an identical test setup and geometrical configuration examined in the previous section for the plain concrete beam. Here, the horizontal running bond pattern is examined as shown in Figure 28. (Reyes et al. 2004, 2008) provide detailed information about the material properties, test setup and procedure.

The contact stiffness at the joints in the brickwork assemblage is estimated based on the ratio between the elastic stiffness of the masonry and the mortar joint thickness, both are provided in the reference study. It is important to note that bricks are split into two pieces defining joints to simulate the cracking phenomenon in masonry units. In discrete meso model, tensile strength within the masonry units and the interface between the units are taken as 7.6 MPa and 5.8 MPa, given in (Reyes et al. 2008). The following contact stiffnesses in normal and shear directions and the mode I fracture energy for bricks are defined as, $k_{n}: 9300 \mathrm{GPa} / \mathrm{m}, k_{s}: 3900 \mathrm{GPa} / \mathrm{m}$ and 107 $\mathrm{N} / \mathrm{m}$, respectively. Note that the dilation angle is set to zero and mode I fracture energy for the mortar joints is assumed as $60 \mathrm{~N} / \mathrm{m}$. The analyzed masonry beam dimension and boundary conditions are shown in Figure 28. 


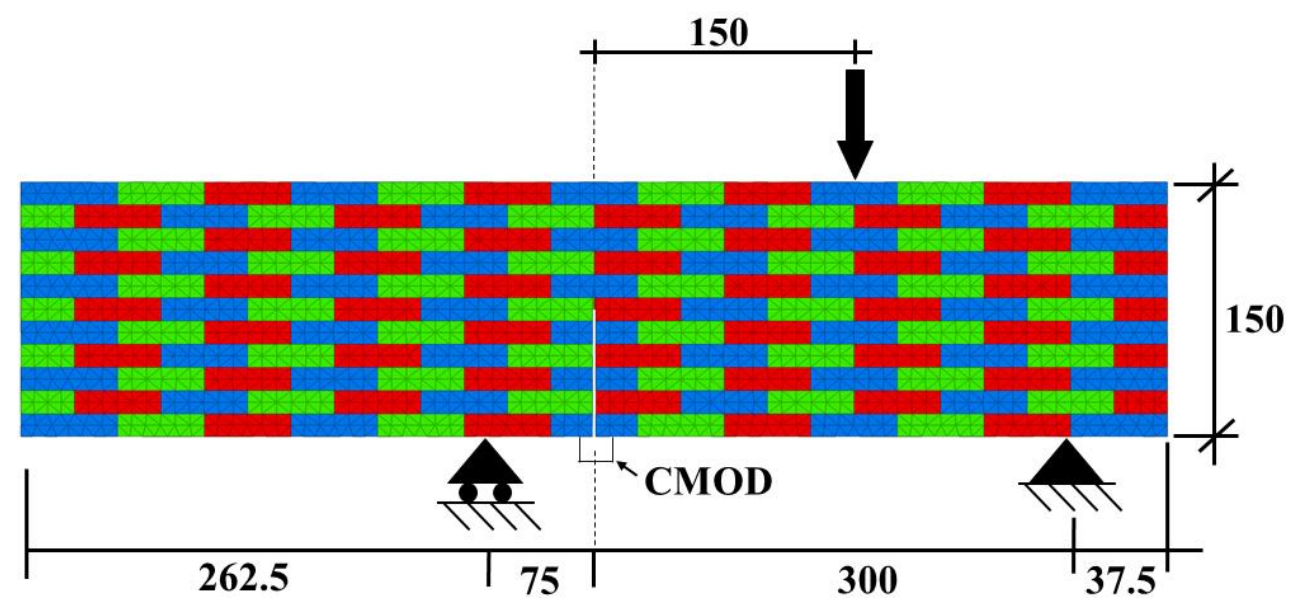

Figure 28. Mixed-mode three point bending test setup given in (Reyes et al. 2008)(Gálvez et al. 1999), dimensions are in $\mathrm{mm}$.

The results obtained from the numerical models are compared with the experimental envelope in Figure 29. Two simplified meso models consisting of different number of sub-contacts are prepared that are referred as coarse (4540 sub-contacts) and fine (16750 sub-contacts). It can be noticed that the higher number of sub-contacts yields better stress distributions through the joints providing a smooth macro behavior (force-CMOD curve), which can be seen in Figure 29 (CMOD means Crack Mouth Opening Displacement). On the other hand, less accurate contact stress distribution is obtained when lower number of sub-contacts are used, resulting in severe stress drops once the capacity at the sub-contact is reached (see Figure 29). Furthermore, it is worth noting that quite similar fracture mode and crack propagation is found via simplified meso models, presented in Figure 30. The step-wise cracks and the failure in the bricks are observed during the analysis. The results from computational models show a good agreement with the experimental findings in terms of failure mode and force displacement behavior. Thus, simplified meso modeling may be considered as an alternative approach to the detailed one for large scale models and structures. 


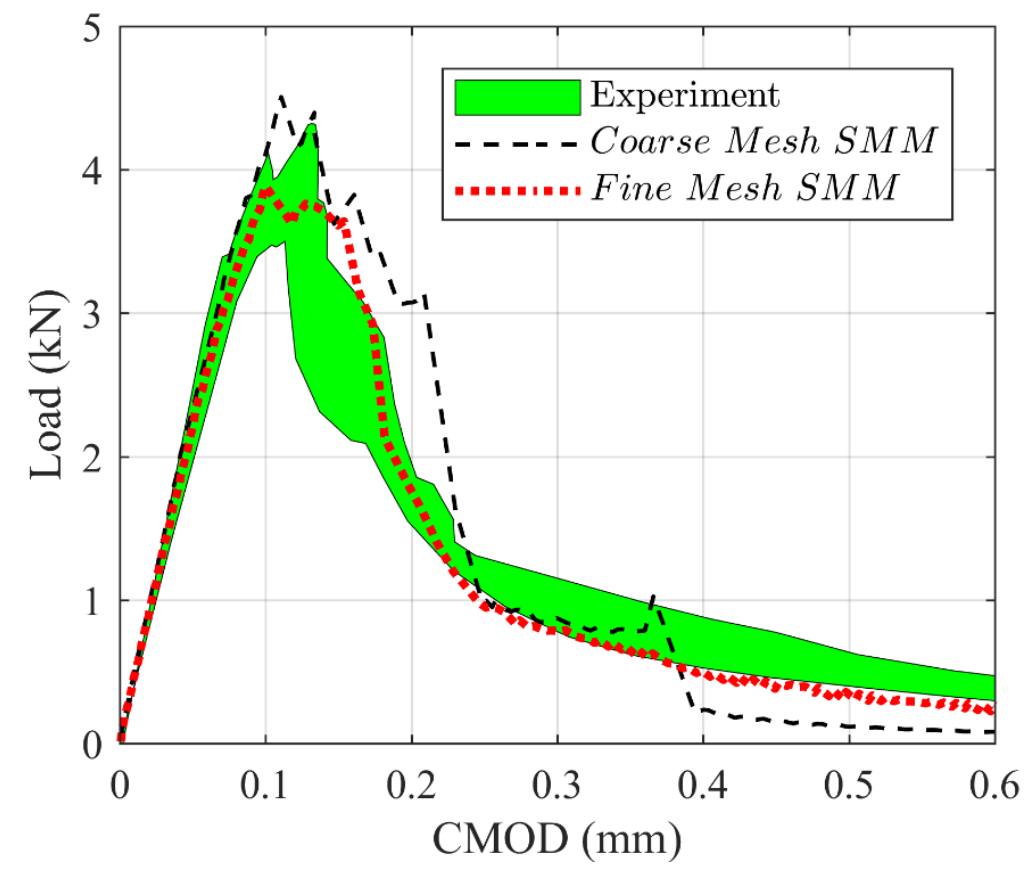

Figure 29. Force vs CMOD response of the masonry beam: Comparison between simplified meso model (SMM) and experimental envelop.

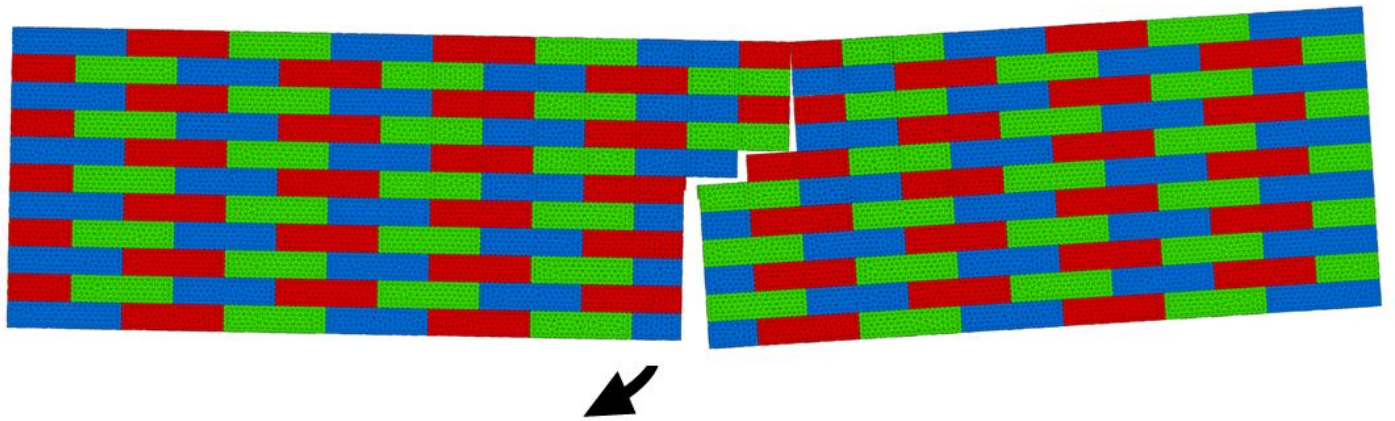

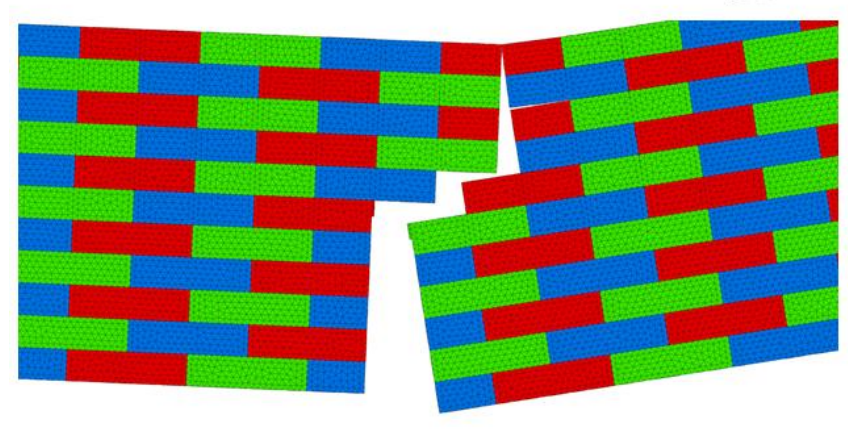

Simplified Meso Model

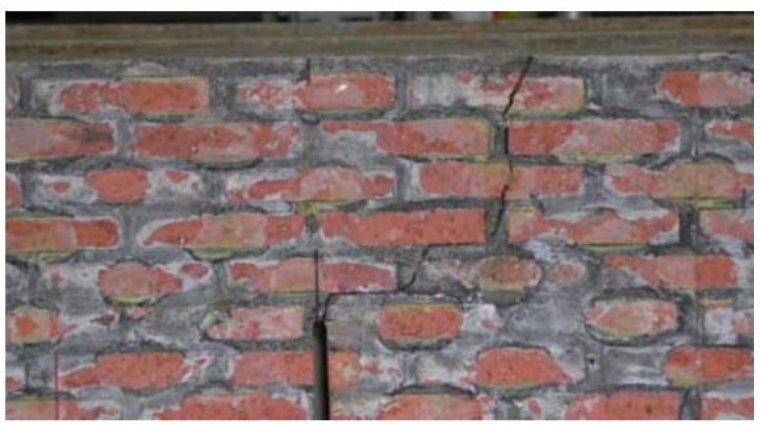

Experiment (Reyes et al., 2004)

Figure 30. Mixed mode cracking in brickwork assemblages; Left: numerical (discrete mesomodel - Fine Mesh), Right: experimental result (Reyes et al. 2004). 


\section{Conclusions}

This study presents a discontinuum approach to simulate the 3D fracture mechanism of concrete and masonry specimens under direct tensile test as an alternative strategy to continuumbased approaches. Proposed detailed numerical modeling strategy successfully reproduces 3D tensile fracture mode of concrete composed of stiff aggregate with a weaker matrix, as well as masonry assemblages made up of unit and mortar. In both cases, the heterogenous form of the material is expressed as a system of polyhedral blocks that interacts through contact points. In addition, a simplified model composed of smooth contact surfaces is presented for large scale modeling purposes. According to the results of the analysis, the following conclusions are derived.

- The smooth contact model has advantages in terms of simplicity and computational cost. However, it is not able to represent the fracture mechanism of the heterogenous materials in detail due to their disordered internal structure. Hence, its application would be more useful in large-scale models.

- In detailed meso-modeling, the crack-induced damage progression is captured successfully, propagating along the block boundaries, and realistic fracture patterns are obtained for both concrete and masonry specimens, even if large blocks are adopted.

- The post-peak response of the examined materials is slightly influenced by the number of grains (or blocks) in detailed numerical models. This is to be expected since the fracture surface changes due to non-uniform (or disordered) morphology of the blocks. As a result of that, interlocking stresses (both normal and shear) may develop during the analyses and slightly influence pre- and post-peak response of the discrete element model. 
- According to the parametric analysis performed on the contact parameters of the detailed model, the cohesion has a considerable effect on the overall tensile capacity when it is less than the specified tensile strength, so such low values should not be adopted.

- Lower fracture energy results in a much more brittle response in the material together with a lower capacity, as expected.

- A detrimental influence of the dilation angle when it is equal to friction angle (associated flow) is found compared to experimental result, especially in the post-peak response of the material. Therefore, lower dilatancy angles should be used at the contacts (i.e. at most one third of the friction angle).

- Furthermore, boundary conditions appear to have a noticeable effect on the material behavior according to the results of the detailed meso models, as also observed in experiments.

- The proposed modeling strategy gives successful results in the analysis of mixed-mode cracking problems that are both presented for concrete and brickwork assemblages via detailed and simplified meso models, respectively.

Overall, it is concluded that the proposed tensile softening contact models utilized with the randomly generated polyhedral geometries provided a good estimation of the behavior of the quasi-brittle materials in terms of capacity, post-peak behavior and failure mechanisms, such as concrete and masonry.

\section{Acknowledgments}

Authors would like to express their gratitude to Itasca Educational Partnership Program (IEP) for their kind support and providing 3DEC software. 


\section{References}

Adami CE, Vintzileou E (2008) Interventions to historic masonries: Investigation of the bond mechanism between stones or bricks and grouts. Mater Struct Constr 41:255-267. doi: $10.1617 / \mathrm{s} 11527-007-9235-\mathrm{Z}$

Bobiński J, Tejchman J (2005) Modelling of Concrete Behaviour with a Non-Local Continuum Damage Approach. Arch Hydro-Engineering Environ Mech 52:243-263.

Bocca P, Carpinteri A, Valente S (1990) Size effects in the mixed mode crack propagation: Softening and snap-back analysis. Eng Fract Mech 35:159-170. doi: 10.1016/00137944(90)90193-K

Bui TT, Limam A, Sarhosis V, Hjiaj M (2017) Discrete element modelling of the in-plane and outof-plane behaviour of dry-joint masonry wall constructions. Eng Struct 136:277-294. doi: 10.1016/j.engstruct.2017.01.020

Chen W, Konietzky H, Liu C, et al (2018) Prediction of Brickwork Failure Using Discrete-Element Method. J Mater Civ Eng 30:06018012. doi: 10.1061/(ASCE)MT.1943-5533.0002431

Cundall PA (1987) Distinct Element Models of Rock and Soil Structure. In: Brown ET (ed) Analytical and Computational Methods in Engineering Rock Mechanics. George Allen Unwin, London, pp 129-163

Cundall PA (1971) A computer model for simulating progressive, large-scale movements in blocky rock systems. In: The International Symposium on Rock Mechanics. pp 47-65

Gálvez JC, Elices M, Planas J (1999) Mixed mode fracture of concrete under proportional and nonproportional loading. Int J Fract 94:267-284. doi: 10.1023/A:1007578814070

Ghazvinian E, Diederichs MS, Quey R (2014) 3D random Voronoi grain-based models for simulation of brittle rock damage and fabric-guided micro-fracturing. J Rock Mech Geotech Eng 6:506-521. doi: 10.1016/j.jrmge.2014.09.001

Hordijk DA (1991) Local approach to fatigue of concrete. Delft University of Technology

ITASCA (2004) 3DEC Universial Discrete Element Code Theory and Background. Minneapolis

Kazerani T (2013) A discontinuum-based model to simulate compressive and tensile failure in sedimentary rock. J Rock Mech Geotech Eng 5:378-388. doi: 10.1016/j.jrmge.2013.07.002

Kazerani T, Zhao J (2010) Micromechanical parameters in bonded particle method for modelling of brittle material failure. Int J Numer Anal Methods Geomech 34:1877-1895. doi: $10.1002 /$ nag.884

Lemos J V. (2007) Discrete Element Modeling of Masonry Structures. Int J Archit Herit 1:190213. doi: $10.1080 / 15583050601176868$

Lemos J V. (2016) Modelling the Dynamics of Masonry Structures with Discrete Elements. Open Constr Build Technol J 10:210-219. doi: 10.2174/1874836801610010210

Lemos J V., Campos Costa A (2017) Simulation of Shake Table Tests on Out-of-Plane Masonry Buildings. Part (V): Discrete Element Approach. Int J Archit Herit 11:117-124. doi: 
$10.1080 / 15583058.2016 .1237587$

Lisjak A, Grasselli G (2014) A review of discrete modeling techniques for fracturing processes in discontinuous rock masses. J Rock Mech Geotech Eng 6:301-314. doi: 10.1016/j.jrmge.2013.12.007

Lourenço PB (1996) Computational strategies for masonry structures. Delf University of Technology

Lourenço PB, Almeida JC, Barros JA (2005) Experimental investigation of bricks under uniaxial tensile testing.

Peerlings RHJ, de Borst R, Brekelmans WAM, Geers MGD (1998) Gradient-enhanced damage modelling of concrete fracture. Mech Cohesive-Frictional Mater 3:323-342. doi: 10.1002/(SICI)1099-1484(1998100)3:4<323::AID-CFM51>3.0.CO;2-Z

Pina-Henriques J, Lourenço PB (2006) Masonry compression: a numerical investigation at the meso-level. Eng Comput 23:382-407. doi: 10.1108/02644400610661163

Pulatsu B, Bretas EM, Lourenço PB (2016) Discrete element modeling of masonry structures: Validation and application. Earthquakes Struct 11:563-582. doi: 10.12989/eas.2016.11.4.563

Pulatsu B, Erdogmus E, Lourenço PB (2019) Comparison of in-plane and out-of-plane failure modes of masonry arch bridges using discontinuum analysis. Eng Struct 178:24-36. doi: 10.1016/j.engstruct.2018.10.016

Pulatsu B, Sarhosis V, Bretas EM, et al (2017) Non-linear static behaviour of ancient free-standing stone columns. Proc Inst Civ Eng - Struct Build 170:406-418. doi: 10.1680/jstbu.16.00071

Quey R, Dawson PR, Barbe F (2011) Large-scale 3D random polycrystals for the finite element method: Generation, meshing and remeshing. Comput Methods Appl Mech Eng 200:17291745. doi: 10.1016/j.cma.2011.01.002

Quey R, Renversade L (2018) Optimal polyhedral description of 3D polycrystals: Method and application to statistical and synchrotron X-ray diffraction data. Comput Methods Appl Mech Eng 330:308-333. doi: 10.1016/j.cma.2017.10.029

Resende R, Lemos JV, Dinis PB (2014) Application of a discontinuity model with softening to the analysis of dam foundations using the Discrete Element Method. In: Konietzky H (ed) 1st International UDEC/3DEC Symposium: Numerical Modelling of Discrete Materials in Geotechnical Engineering, Civil Engineering and Earth Sciences. pp 249-255

Reyes E, Casati MJ, Gálvez JC (2004) Normal / shear cracking of brickwork masonry. In: Fracture mechanics of concrete structures. pp 415-422

Reyes E, Casati MJ, Gálvez JC (2008) Cohesive crack model for mixed mode fracture of brick masonry. Int J Fract 151:29-55. doi: 10.1007/s 10704-008-9243-1

Rots JG (1988) Computational modeling of concrete fracture. Delf University of Technology

Rots JG, de Borst R (1989) Analysis of concrete fracture in direct tension. Int J Solids Struct 25:1381-1394.

Sarhosis V, Lemos J V. (2018) A detailed micro-modelling approach for the structural analysis of 
masonry assemblages. Comput Struct 206:66-81. doi: 10.1016/j.compstruc.2018.06.003

Van der Pluijm R (1997) Nonlinear behavior of masonry under tension. Heron 42:25-54.

Van Mier JGM, Man HK (2009) Some notes on microcracking, softening, localization, and size effects. Int J Damage Mech 18:283-309. doi: 10.1177/1056789508097545

van Mier JGM, van Vliet MR. (2002) Uniaxial tension test for the determination of fracture parameters of concrete State of the Art. Eng Fract Mech 69:235-247.

Vasconcelos G de FM de (2005) Experimental investigations on the mechanics of stone masonry: Characterization of granites and behavior of ancient masonry shear walls. Universidade do Minho

Vintzileou EN, Adami CEN (2009) The bond mechanism in stone- or brick-to-grout interfaces. Strain 45:400-409. doi: 10.1111/j.1475-1305.2008.00545.x 